\section{Microenvironmental regulation of the IL-23R/IL-23 axis overrides chronic lymphocytic leukemia indolence}

\author{
Giovanna Cutrona, ${ }^{1 *}{ }^{\dagger}$ Claudio Tripodo, ${ }^{2 *}$ Serena Matis, ${ }^{1}$ Anna Grazia Recchia, ${ }^{3,4}$ \\ Carlotta Massucco, ${ }^{1}$ Marina Fabbi, ${ }^{5}$ Monica Colombo, ${ }^{1}$ Laura Emionite, ${ }^{6}$ Sabina Sangaletti, ${ }^{7}$ \\ Alessandro Gulino, ${ }^{2}$ Daniele Reverberi, ${ }^{1}$ Rosanna Massara, ${ }^{1}$ Simona Boccardo, ${ }^{8}$ Daniela de Totero, ${ }^{1}$ \\ Sandra Salvi, ${ }^{8}$ Michele Cilli, ${ }^{6}$ Mariavaleria Pellicanò, ${ }^{3,4}$ Martina Manzoni, ${ }^{9,10}$ Sonia Fabris, ${ }^{10}$ \\ Irma Airoldi, ${ }^{11}$ Francesca Valdora, ${ }^{1,12}$ Silvano Ferrini, ${ }^{5}$ Massimo Gentile, ${ }^{3,4}$ Ernesto Vigna, ${ }^{3,4}$ \\ Sabrina Bossio, ${ }^{4}$ Laura De Stefano, ${ }^{4}$ Angela Palummo, ${ }^{4}$ Giovanni laquinta, ${ }^{4}$ Martina Cardillo, ${ }^{12}$ \\ Simonetta Zupo, ${ }^{13}$ Giannamaria Cerruti, ${ }^{13}$ Adalberto Ibatici, ${ }^{14}$ Antonino Neri, ${ }^{9,10}$ Franco Fais, ${ }^{1,12}$ \\ Manlio Ferrarini, ${ }^{15}$ Fortunato Morabito ${ }^{3,4}$
}

Although the progression of chronic lymphocytic leukemia (CLL) requires the cooperation of the microenvironment, the exact cellular and molecular mechanisms involved are still unclear. We investigated the interleukin (IL)-23 receptor (IL-23R)/IL-23 axis and found that circulating cells from early-stage CLL patients with shorter timeto-treatment, but not of those with a more benign course, expressed a defective form of the IL-23R complex lacking the IL-12Rß1 chain. However, cells from both patient groups expressed the complete IL-23R complex in tissue infiltrates and could be induced to express the IL-12Rß1 chain when cocultured with activated T cells or CD40L ${ }^{+}$ cells. CLL cells activated in vitro in this context produced IL-23, a finding that, together with the presence of IL-23 in CLL lymphoid tissues, suggests the existence of an autocrine/paracrine loop inducing CLL cell proliferation. Interference with the IL-23R/IL-23 axis using an anti-IL-23p19 antibody proved effective in controlling disease onset and expansion in xenografted mice, suggesting potential therapeutic strategies.

\section{INTRODUCTION}

Chronic lymphocytic leukemia (CLL) involves the monoclonal expansion of $\mathrm{CD}^{+} \mathrm{B}$ lymphocytes in the bone marrow, peripheral blood, and lymphoid organs (1). Most patients present with an indolent disease and may not require treatment for many years, whereas a minority of patients (about 30\%) display a rather aggressive disease course requiring early treatment. Clinical heterogeneity may be attributed to both clone-intrinsic biological features and clone-extrinsic events, given the fact that signals from the surrounding microenvironment are increasingly recognized as determinants of clone fitness and progression (2-5).

The mechanisms underlying CLL cell clonal expansion are only partially understood. In vivo cell kinetic studies in patients have demonstrated that CLL cells have a substantially higher proliferative rate than originally estimated, which challenged the view that the CLL clone en-

\footnotetext{
${ }^{1}$ Molecular Pathology Unit, Istituto di Ricovero e Cura a Carattere Scientifico (IRCCS) Azienda Ospedaliera Universitaria (AOU) San Martino-Istituto Nazionale per la Ricerca sul Cancro (IST), 16132 Genoa, Italy. ${ }^{2}$ Tumor Immunology Unit, Department of Health Science, Human Pathology Section, University of Palermo School of Medicine, 90127 Palermo, Italy. ${ }^{3}$ Hematology Unit, Department of Onco-Hematology, Azienda Ospedaliera (AO) of Cosenza, 87100 Cosenza, Italy. ${ }^{4}$ Biotechnology Research Unit, Aprigliano, AO/Azienda Sanitaria Provinciale (ASP) of Cosenza, 87051 Cosenza, Italy. ${ }^{5}$ Biotherapy Unit, IRCCS AOU San Martino-IST, 16132 Genoa, Italy. ${ }^{6}$ Animal Facility, IRCCS AOU San Martino-IST, 16132 Genoa, Italy. ${ }^{7}$ Molecular Immunology Unit, IRCCS Istituto Nazionale Tumori, 20134 Milan, Italy. ${ }^{8}$ Division of Histopathology and Cytopathology, IRCCS AOU San Martino-IST, 16132 Genoa, Italy. ${ }^{9}$ Department of Oncology and Hemato-Oncology, University of Milano, 20122 Milan, Italy. ${ }^{10} \mathrm{Hematology}$ Unit, Fondazione IRCCS Ca'Granda, Ospedale Maggiore Policlinico, 20122 Milan, Italy. ${ }^{11}$ Stem Cell Laboratory and Cell Therapy Center, IRCCS Istituto Giannina Gaslini, 16147 Genoa, Italy. ${ }^{12}$ Department of Experimental Medicine, University of Genoa, 16132 Genoa, Italy. ${ }^{13}$ Molecular Diagnostic Unit, Division of Histopathology and Cytopathology, IRCCS AOU San Martino-IST, 16132 Genoa, Italy. ${ }^{14}$ Hematology and Bone Marrow Transplantation Unit, IRCCS AOU San Martino-IST, 16132 Genoa, Italy. ${ }^{15}$ Scientific Direction, IRCCS AOU San Martino-IST, 16132 Genoa, Italy.

*These authors contributed equally to this work.

tCorresponding author. Email: giovanna.cutrona@hsanmartino.it
}

dorses minimal proliferative capacity despite conspicuous resistance to cell death $(6,7)$. Proliferation of CLL cells occurs primarily in peripheral lymphoid organs, specifically within the so-called proliferating centers of infiltrated lymphoid tissues, and is driven by signals delivered by the surrounding cells, by cytokines, and even by the CLL cell B cell receptor (BCR) (8-10). Furthermore, proinflammatory cytokines have been variably demonstrated to identify CLL subsets having more aggressive disease and worse survival $(11,12)$. Finally, many CLL clones express BCR with polyreactivity and/or self-reactivity, which could bind (although with low affinity) to a number of self-antigens expressed by surrounding cells, contributing to their activation and subsequent susceptibility to growth signals $(13,14)$. Likewise, a similar function may be exerted by the recognition of antigens exposed by apoptotic cells or of internal epitopes of the CLL BCR itself (15-18).

Interleukin-23 (IL-23) is a pleiotropic cytokine of the IL-6 superfamily involved in the bridging of adaptive and innate immunity and in tissue remodeling (19). IL-23 is a heterodimeric cytokine composed of a p19 subunit and a p40 subunit, which is common to IL-12. IL-23 is predominantly produced by myeloid dendritic cells and type $1 \mathrm{mac}-$ rophages in response to microbial or host immune stimuli and is involved in the regulation of immune responses against infections and tumor development through the engagement of the IL-23 receptor (IL-23R) (20-22). The IL-23R is a heterodimeric complex consisting of an IL-12R $\beta 1$ chain (also common to the IL-12R) and a specific IL-23R subunit (22). To date, the demonstration of functional IL23R complex expression in normal B cells has been confined to early $B$ lymphocytes, germinal center B cells, and plasma cells $(23,24)$. The IL-23R heterodimer is also expressed by acute lymphoblastic leukemia (ALL) cells, follicular lymphoma (FL), diffuse large B cell lymphoma (DLBCL), and myeloma cells (23-26).

Here, we demonstrate that circulating CLL cells of early-stage, Binet A patients variably express the IL-23R subunit in the absence of the IL-12R $\beta 1$ 
chain and that the expression of the IL-23R subunit positively correlates with adverse prognostic factors and a higher risk of therapy need. We also provide evidence of a regulation of the IL-23R complex by the microenvironment and unveil an autocrine/paracrine loop involving IL-23R complex up-regulation and IL-23 synthesis in CLL clones. Finally, we demonstrate that this loop may represent a therapeutic target because in vivo treatment with an anti-IL-23p19 monoclonal antibody (mAb) ( $\alpha \mathrm{IL}-23 \mathrm{p} 19)$ eradicated CLL clones in xenografted mice.

\section{RESULTS}

\section{Uncoupled IL-23R expression characterizes circulating peripheral CLL cells and identifies high-risk early-stage patients}

The surface expression of the two chains of the IL-23R complex (IL-23R and IL-12R $\beta 1$ subunits) was investigated in circulating CLL cells of 57 consecutive Binet stage A patients enrolled in a multicenter prospective trial. Although the expression of the IL-23R chain varied from high to low (Fig. 1, A to C), that of IL-12R $\beta 1$ was consistently low or absent in CLL cells (gated as $\mathrm{CD} 19^{+} \mathrm{CD}^{+}$cells) from all the peripheral blood mononuclear cell (PBMC) suspensions analyzed (Fig. 1C). The uncoupled expression of IL-23R and IL-12R $\beta 1$ side chains was also confirmed by double-marker immunofluorescence (IF) studies using cytospin preparations (Fig. 1B). IL-23R was expressed by T cells and natural killer (NK) cells from the same CLL cases, which also showed a substantial proportion of IL-12R $\beta 1^{+}$cells (see Fig. 1D). No significant differences were observed in the expression of the IL-23R complex by T cells and NK cells from CLL cases classified as IL-23R-positive or IL-23R-negative (see Fig. 1).

The study of IL-23R expression was extended to the PBMCs of an additional 209 CLL patients in the trial. The variability of IL-23R chain expression (median percentage expression, 26\%; range, 3.9 to 91.2) (Fig. 1E) allowed stratification of patients into two groups designated as IL-23R $\mathrm{R}^{\text {high }}(\geq 23 \%, n=152)$ or IL-23R $\mathrm{R}^{\text {low }}(<23 \%, n=114)$, based on receiver operating curve (ROC) analysis (as described in Materials and Methods). Notably, IL-23R chain expression was significantly correlated only with immunoglobulin heavy chain variable region $(I G H V)$ gene mutational status $(P=0.049)$ when considered together with other prognostic markers (table $\mathrm{S} 1$ ).

Clinical information was available for 219 cases, and we could explore a possible correlation between IL-23R chain expression by CLL cells and time to first treatment (TTFT). Of these cases, 63 met the more recent diagnostic criteria of clinical monoclonal B lymphocytosis $(\mathrm{MBL})(27,28)$. The median follow-up was 36 months (range, 6 to 63 months); 8 of 97 IL-23R ${ }^{\text {low }}$ and 26 of 122 IL-23R ${ }^{\text {high }}$ CLL cases progressed and required treatment. The 3 -year TTFT probability of IL-23R ${ }^{\text {low }}$ patients was $91.6 \%$ compared to $85.0 \%$ of IL-23R ${ }^{\text {high }}$ cases (Fig. 1E). Univariate Cox analysis showed that CD38-positive, IGHV gene-unmutated, zeta chain-associated protein kinase 70 (ZAP70)-positive cases and patients with a peripheral B lymphocytosis of $\geq 5000 / \mathrm{mm}^{3}$ had a higher risk of starting treatment compared to CD38-negative, IGHV gene-mutated, ZAP-70-negative, and MBL cases. In a Cox multivariate model, IL-23R chain expression remained significant [hazard ratio $(\mathrm{HR})=2.8,95 \%$ confidence interval $(\mathrm{CI})=1.2$ to $6.5, P=0.014]$ in predicting TTFT, together with $I G H V$ gene mutational status and B lymphocytosis $\geq 5000 / \mathrm{mm}^{3}$ (Fig. 1F). The same analysis carried out by a bootstrapping Cox regression model provided similar results (table S2).

\section{Complete IL-23R complex expression is dependent on the CLL tissue microenvironment}

Next, we investigated whether the uncoupled expression of the two chains of the IL-23R complex also characterized CLL cells within the tissue microenvironment. First, we evaluated the expression of the IL-23R chain in tissue samples from 16 CLL patients, collected at diagnosis using in situ immunolocalization analyses. A variable expression of the IL-23R chain was observed in CLL lymph node (LN) infiltrates, which comprised cases with few scattered IL-23R chainexpressing cells intermingling with a majority of IL-23R chain-negative elements (10 of 16 cases) (Fig. 2A, left) and cases with a prominent IL-23R chain expression in the majority of the lymphoid infiltrates (6 of 16) (Fig. 2A, right). The large majority of IL-23R chain-expressing cells also expressed CD20 (Fig. 2B, left). IL-12R $\beta 1$ was present within LN infiltrates of IL-23R chain-positive CLL cases, and its expression mainly characterized CD20-positive CLL cells (Fig. 2B, right). Double-marker IF analysis showed that IL-12R $\beta 1$ expression was not homogeneous, being highly expressed and colocalized with the IL-23R chain in some areas of the LN infiltrates or barely expressed in other LN areas despite a high IL-23R chain staining (Fig. 2C). Double-marker IF analyses revealed that, within CLL nodal infiltrates, those areas showing dense macrophage infiltration or higher CD40L expression also corresponded to areas with higher IL-12R $\beta 1$ expression (Fig. 2, D and E).

\section{Costimulatory signals modulate in vitro IL-12Rß1 chain expression in CLL}

Next, we analyzed whether CLL cell activation resulted in upregulation of either IL-23R or IL-12R $\beta 1$ or both receptors. First, we cocultured purified CLL cells in the presence of a CD40L-expressing murine NIH-3T3 cell line (CD40L-TC) or with control cells stably transfected with the plasmid internal ribosomal entry site (pIRES) vector alone (Mock) (29). After 24 to 48 hours of culture, we found a slight, although significant, induction of the IL-23R chain and a significant up-regulation of IL-12R $\beta 1$ expression in both IL-23R high and IL-23R ${ }^{\text {low }}$ cases (Fig. 3A). The cells positive for the IL-23R chains were identified within the gated populations of viable cells (fig. S1, $\mathrm{A}$ and $\mathrm{B}$ ), which also comprised $\mathrm{CD}^{+} 0^{+}$and $\mathrm{CD}^{+} 6^{+}$cells (fig. S1, C and D). The small cells shown in both Fig. $3 \mathrm{~A}$ and fig. $\mathrm{S} 1$ consisted of annexin V/propidium iodide (PI) double-positive dead cells (see fig. S1, A and B). Figure 3B summarizes data from 13 CLL cases ( 3 of 13 being IL-23R $\mathrm{R}^{\text {low }}$ before culture; table S3). In all cases, up-regulation of the IL-23R complex was observed, together with the induction of the IL-12R $\beta 1$. Overall, these phenomena were more marked in the CLL cases classified as IL-23R $\mathrm{R}^{\text {high }}$. These data were corroborated by the observation of an increased production of IL-12R $\beta 1$ mRNA by stimulated CLL cells (see fig. S2).

The IL-23R complex expression was similarly induced upon culturing PBMCs from CLL patients in the presence of CD3/CD28 beads and IL-2 (Fig. 3, C and D). Under these conditions, autologous $\mathrm{T}$ cells present in the suspensions were activated and could, in turn, activate CLL cells. At the end of the culture, the cells were analyzed by flow cytometry. Only viable cells were gated, and the CLL cells present in the suspension were identified as $\mathrm{CD}^{+} \mathrm{CD} 19^{+}$cells. This gated CLL cell population was evaluated for the expression of the IL-23R complex (Fig. 3C). To demonstrate that IL-23R complex up-regulation was not simply due to a selection of preexisting IL-23R complexpositive subclones, PBMCs from CLL patients were depleted of IL23R complex-positive cells using immunomagnetic separation beads 

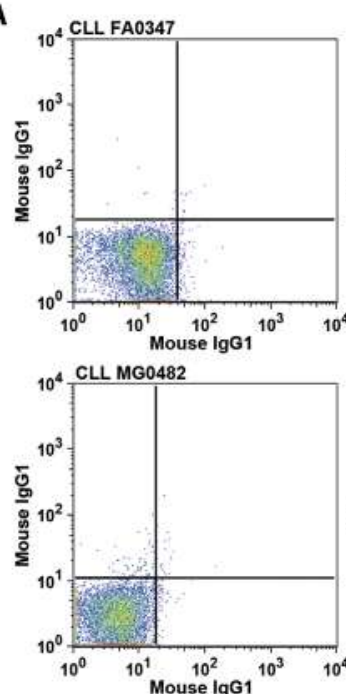

C

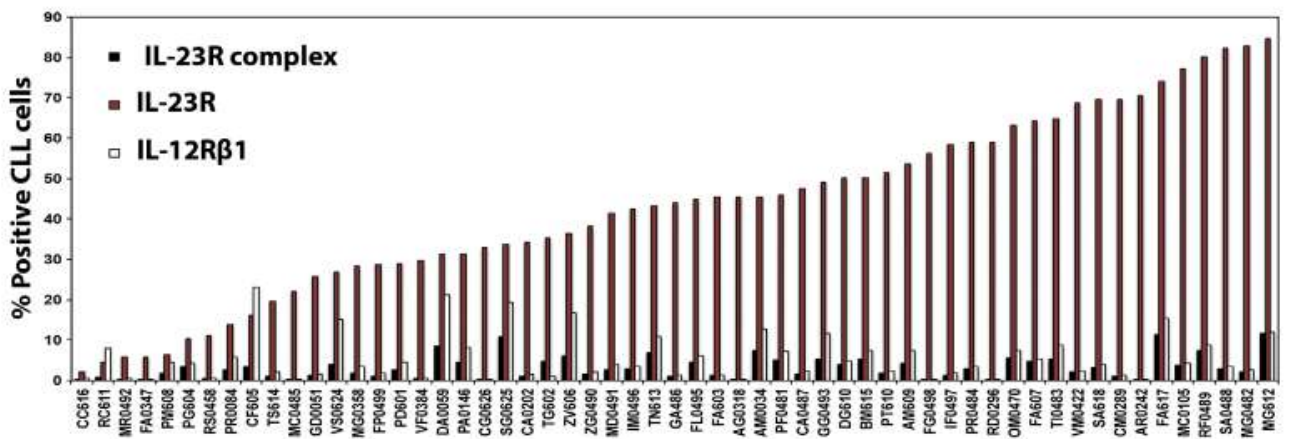

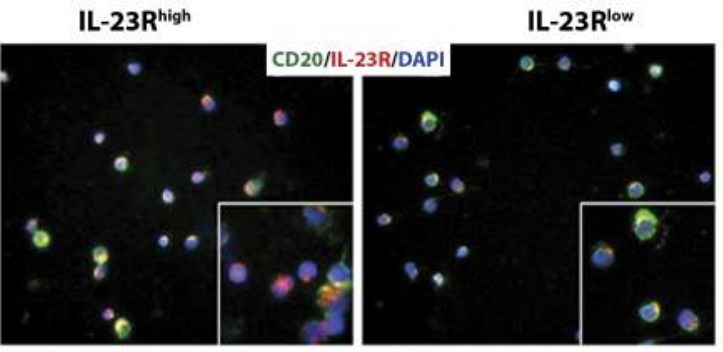

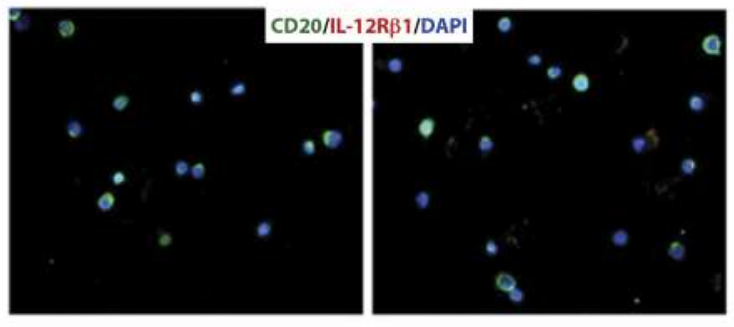

D
E

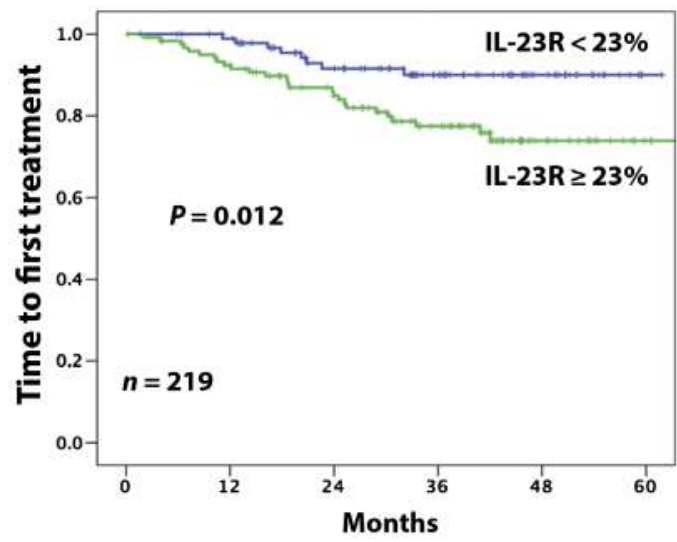

$\mathbf{F}$

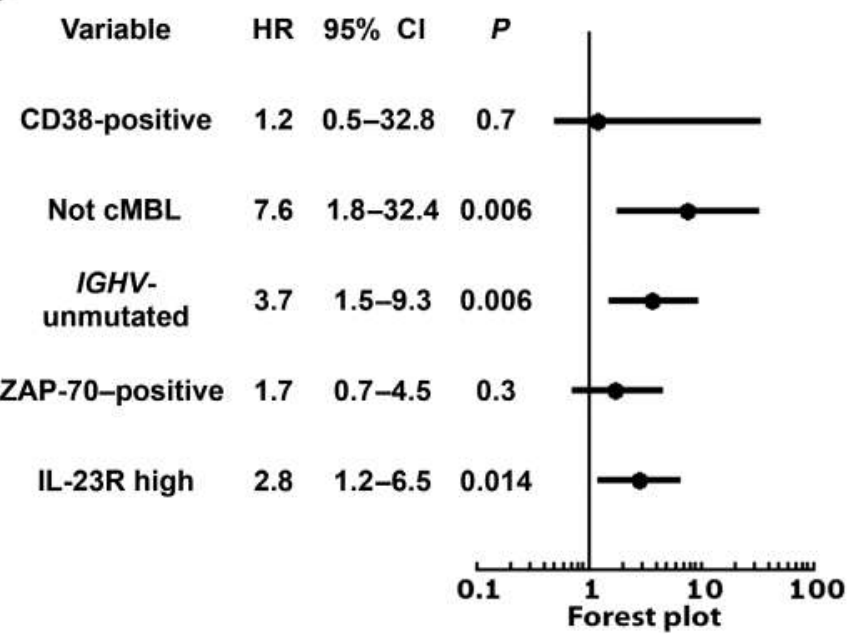

Fig. 1. Evaluation of IL-23R and IL-12Rß1 chain expression in CLL. (A) Two representative chronic lymphocytic leukemia (CLL) cases, with low and high interleukin-23 receptor (IL-23R) expression, respectively, analyzed by flow cytometry. CLL cells were gated as $\mathrm{CD} 19^{+} \mathrm{CD} 5^{+}$cells. IgG1, immunoglobulin G1. (B) IL-23R and IL-12R 1 1 chain expression evaluated by immunocytochemistry on cytospin smears of CLL peripheral blood samples. DAPI, 4',6-diamidino-2-phenylindole. (C) IL-12R 31 chain expression in 57 consecutive cases featuring different IL-23R chain expression. (D) Expression of IL-23R and IL-12R $\beta 1$ by CD $5^{+} \mathrm{CD} 19^{-}[\mathrm{T}$ cells + natural killer cells (T $+\mathrm{NK}$ cells)] from the peripheral blood of the same CLL cases shown in (C) $(n=57)$. Statistical comparisons were carried out by Wilcoxon tests. Asterisks indicate statistically significant $P$ values $(P<0.05)$. (E) Kaplan-Meier curves comparing time to first treatment of IL-23R ${ }^{\text {high }}(n=97)$ or IL-23R ${ }^{\text {low }}(n=122) C L L$ cases. Statistical significance of associations between individual variables and survival was calculated using the log-rank test. (F) Cox multivariate analysis showing that IL-23R chain expression maintains an independent prognostic impact in the presence of other prognostic indicators $(P=0.014)$. $\mathrm{HR}$, hazard ratio; $\mathrm{Cl}$, confidence interval; $\mathrm{CMBL}$, clinical monoclonal $\mathrm{B}$ lymphocytosis; $I G H V$, immunoglobulin heavy chain variable region; ZAP-70, zeta chain-associated protein kinase 70. 
Fig. 2. Analysis of CLLlymph nodes. (A)Two representative cases (of the 16 examined) expressing low $(n=10)$ or high $(n=6)$ IL-23R chain (magnification, $\times 200)$. (B) Doublemarker immunofluorescence (IF) analysis of IL-23R chain (left) or IL-12R $\beta 1$ chain (right) and CD20 in a representative lymph node displaying high expression of the IL-23R chain ( $n=6$ of 16 ) (magnification, $\times 200)$. (C) Doublemarker IF analysis of IL-23R and IL-12Rß1 showing foci of higher and lower IL-12Rß1 expression (dashed circles; magnification, $\times 100$ ). (D) Double-marker IF analysis of IL-12R 31 and CD68 showing higher expression of IL-12Rß1 in foci with higher CD68-expressing cell density. (E) Double-marker IF analysis showing different representative areas of the same lymph node with lower (top) and higher (bottom) IL-12R $\beta 1$ expression and corresponding CD40L expression (magnification, $\times 200$ ). (B to E) Microphotographs are relative to one representative lymph node (of six evaluated) displaying IL-23R $\mathrm{R}^{\text {high }}$ chain. IF microphotographs are representative of analyses on at least 5 for low-power magnification $(\times 100)$ or 10 for high-power magnification $(\times 200$ and $\times 400)$ microscopic fields performed on each lymph node sample.

before autologous $\mathrm{T}$ cell activation (fig. S3). After depletion and stimulation, expression of the IL-23R complex was observed, supporting the notion of de novo expression of receptor structures upon engagement of costimulatory pathways. CLL cells cultured with stimulated T cells were induced to up-regulate both activation (CD38; Fig. 3, E and F) and proliferation (Ki67; Fig. 3, G and H) markers. Consistently, within areas of high IL-12R $\beta 1$ expression in tissue sections, CLL cells showed increased Ki67 signals (Fig. 3I).

\section{CLL cells produce IL-23 in vivo and in vitro}

Subsequently, we investigated the presence of IL-23 in LN tissue specimens from CLL patients. There were two groups of LNs, that is, those that were strongly IL-23-positive (Fig. 4A, left) and those that were almost IL-23-negative (Fig. 4A, right). This distribution was similar to that already shown for IL-23R (see Fig. 2A). There was a clear correlation between the presence of IL-23R and IL-23 in the same infiltrated tissue areas (as shown in Fig. 4B).

A definite increase of IL-23 secretion was observed in CLL cell supernatants after priming with CD40L-TC $(n=18)$ or activated autologous T cells $(n=7)$ (Fig. 4, C and D). Finally, the CLL cells that expressed the IL-23R complex upon in vitro activation with CD40LTC were also those that contained abundant intracytoplasmic IL-23 chains as assessed by flow cytometry (see fig. S4).

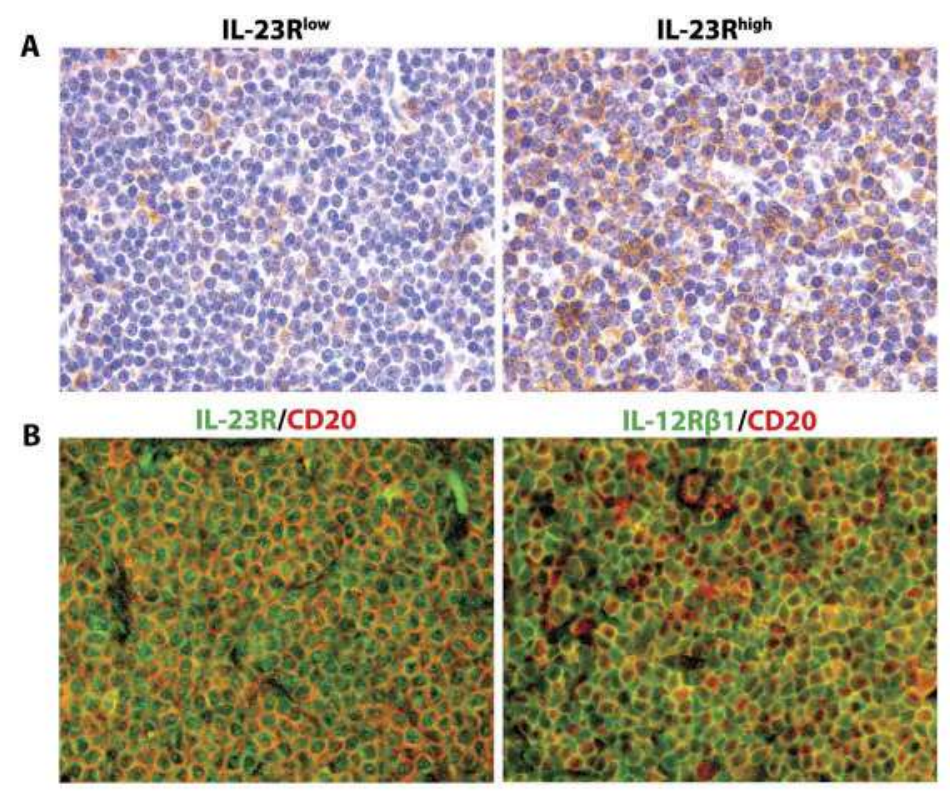

C
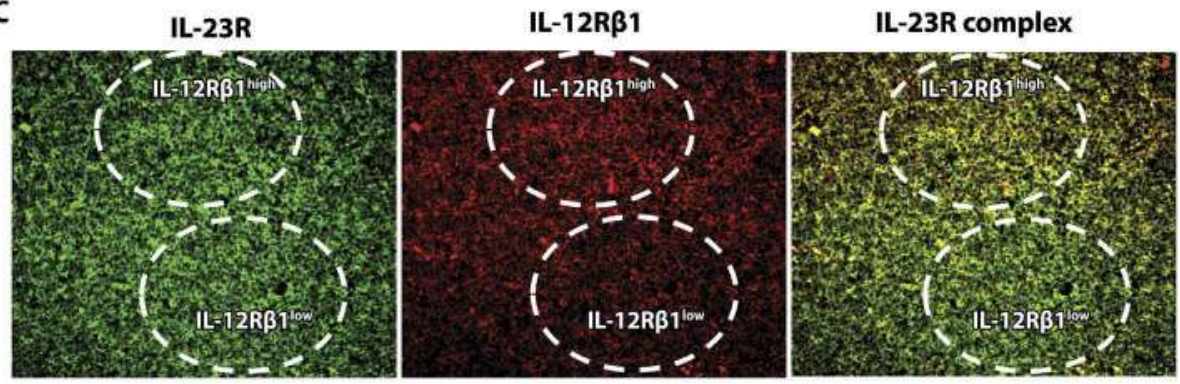

D
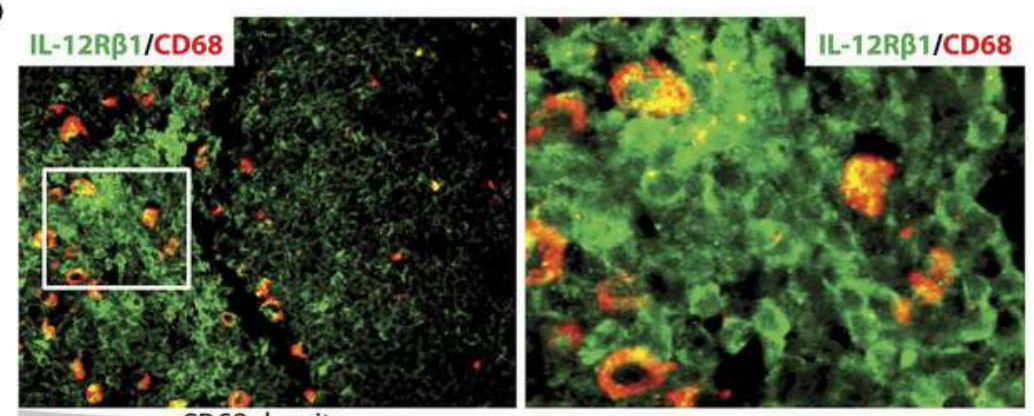

E
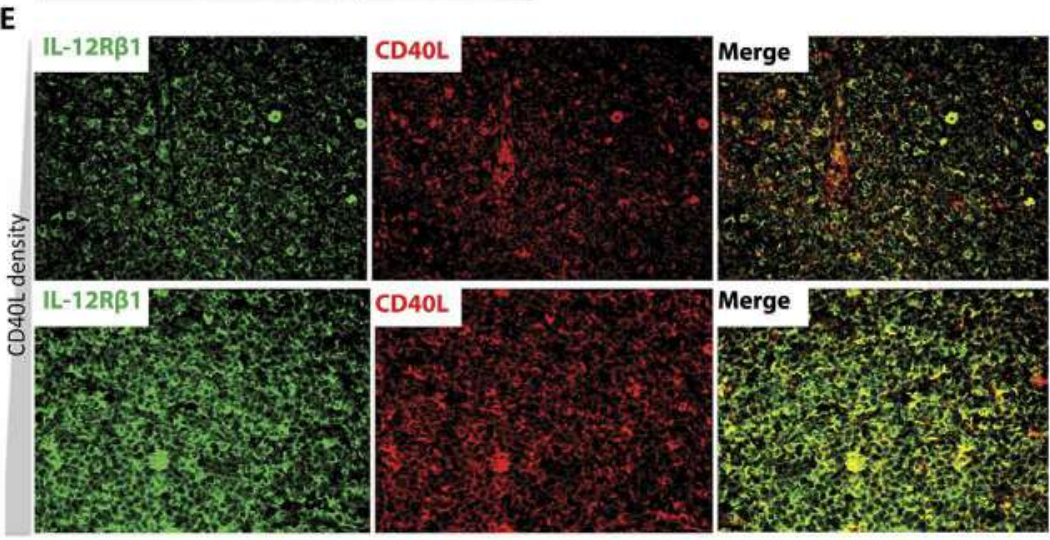
Fig. 3. In vitro induction of IL-12Rß1 chain expression.

(A) Peripheral mononuclear CLL cells from two representative CLL cases (IL-23R ${ }^{\text {low }}$ and IL-23R ${ }^{\text {high }}$, respectively) were cocultured with CD40Lexpressing $\mathrm{NIH}-3 \mathrm{~T} 3$ (CD40L-TC) or control NIH-3T3 cells expressing an empty vector (Mock) for 48 hours and then analyzed for IL-23R complex expression by flow cytometry. Only viable cells were gated, as indicated (left), and of these, $\mathrm{CD}^{+} \mathrm{CD} 19^{+}$cells (middle) were analyzed for IL-23R chain expression (right). For further details, see fig. S1. SSC-H, side scatter height; $\mathrm{FSC}-\mathrm{H}$, forward scatter height. (B) Time course analysis of IL-23R complex (top), IL-23R (middle), and IL-12Rß1 (bottom) chains evaluated by flow cytometry before (TO) and after CD40L engagement in $13 \mathrm{CLL}$ cases. See table $\mathrm{S} 3$ for a summary of patient features. The $P$ values shown are relative to 48 -hour cell cultures (Wilcoxon test). (C) Time course experiments showing a representative test on a CLL case (PD601). Peripheral blood mononuclear cells (PBMCs) were cultured in medium alone or in the presence of $\mathrm{CD} 3 / \mathrm{CD} 28$ beads and IL-2, and cells were harvested at the indicated times. Analysis of the IL-23R chain expression (bottom) was carried out on CLL cells gated for CD5 and CD19 (top). (D) IL-23R-complex expression by the CLL cells of 14 cases analyzed after a 120-hour coculture, as described in (C). $P$ value shown $\left({ }^{* *} P=\right.$ 0.0001 ) refers to the three pairs analyzed (Wilcoxon test). (E) CD38 expression on CLL cells after a 120 -hour culture in
A
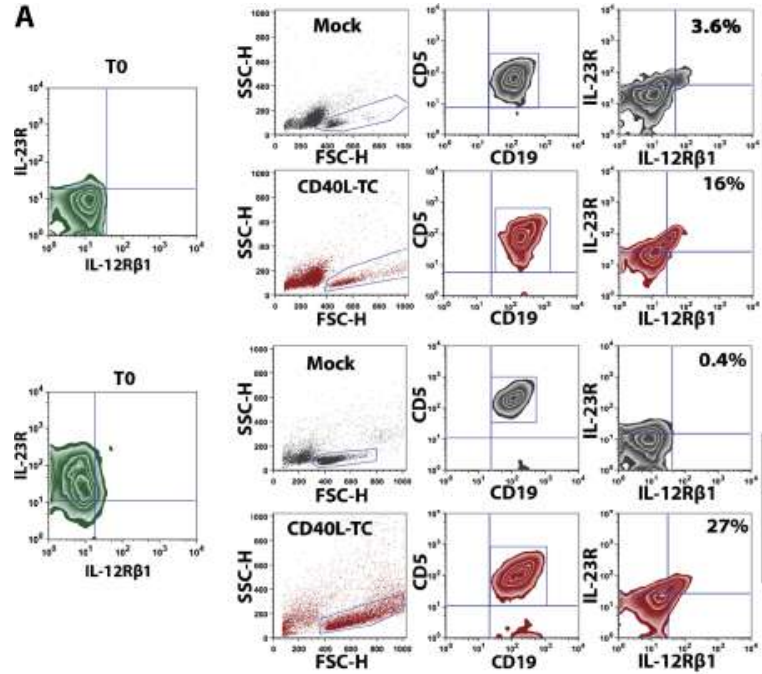

C
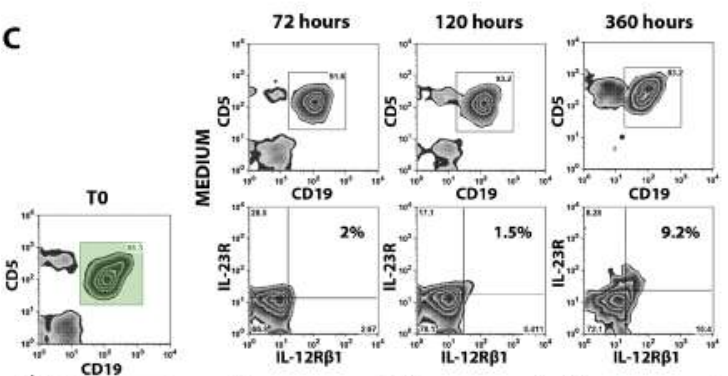$$
\text { 要, }
$$
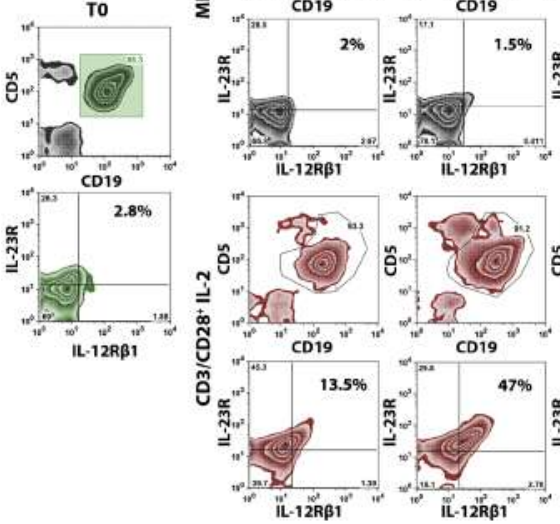

G
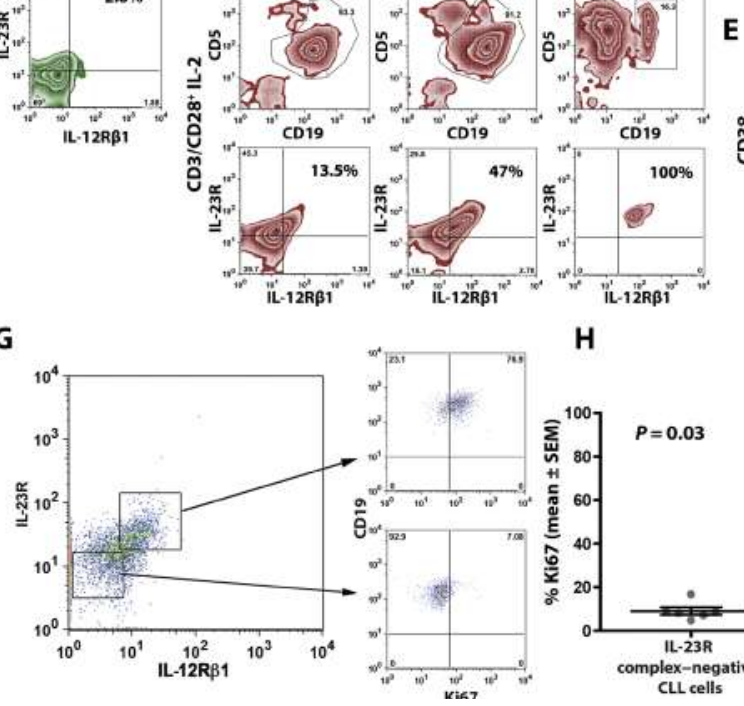
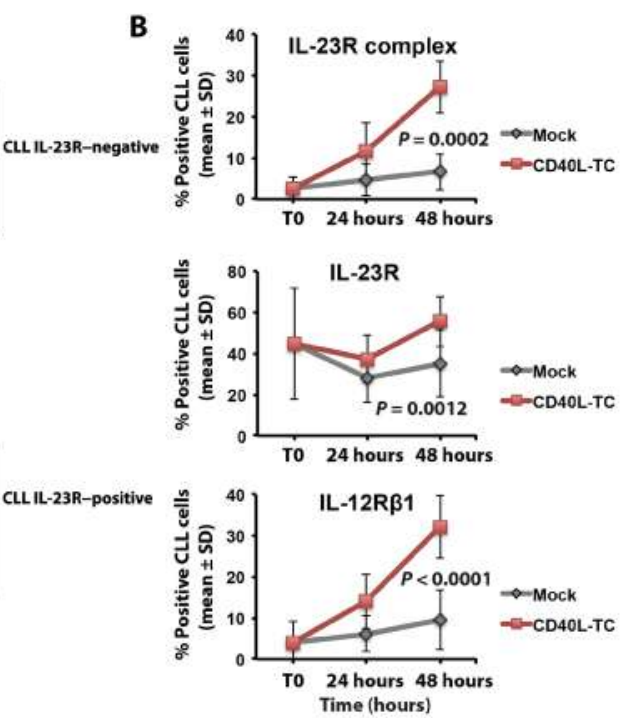

D

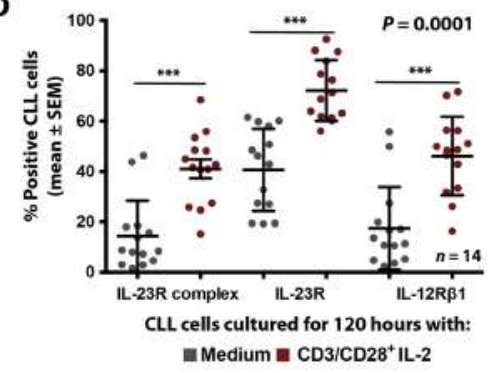

E

H

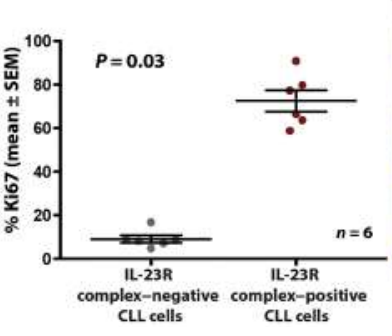

IL-23R complex-negative IL-23R complex-positive

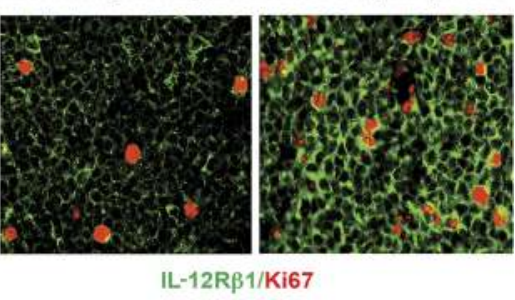

presence of autologous activated T cells and (F) evaluation of IL-23R complex expression on CD38-positive or CD38-negative cells ( $n=11$ CLL cases) (Wilcoxon test). (G) Ki67 expression by IL-23R complex-positive and IL-23R complex-negative CLL cells, respectively. CLL cells, cultured in the presence of activated autologous T cells as in (D), were stained for the indicated receptor chain. $\mathrm{CD}^{+} \mathrm{CD} 19^{+} \mathrm{CLL}$ cells were gated and evaluated for both Ki67 and IL-23R chain expression. (H) Mean and SEM of Ki67 expression by the cells from six CLL cases treated and analyzed as described in (G) (Wilcoxon test). (I) Double-marker IF analysis showing different representative areas of the same lymph node with lower (left) and higher (right) IL-12R $\beta 1$ expression and corresponding Ki67 expression (magnification, $\times 200$ ). IF microphotographs are relative to a representative lymph node (of six evaluated) displaying IL-23R ${ }^{\text {high }}$ chain and of at least 10 microscopic fields performed on each lymph node sample.

Collectively, these data suggest that the CLL microenvironment elicits an autocrine/paracrineloop involving IL-23R complex up-regulation and IL-23 synthesis. Notably, in vitro IL-23 production could be induced in all CLL clones irrespective of whether they were initially classified as IL-23R $\mathrm{R}^{\text {high }}$ or IL-23R ${ }^{\text {low }}$.

\section{IL-23R complex expression is minimally induced or not induced after coculture of CLL cells with stromal cells or nurse-like cells or after BCR cross-linking}

We evaluated whether coculture of CLL cells with stromal cells or nurselike cells (NLCs) results in the induction of IL-23R complex expression. 


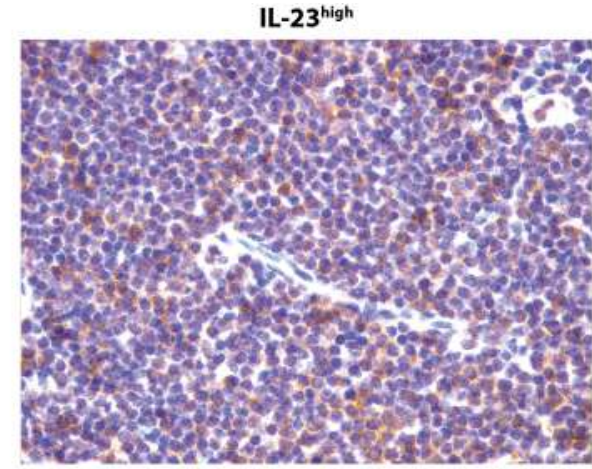

B

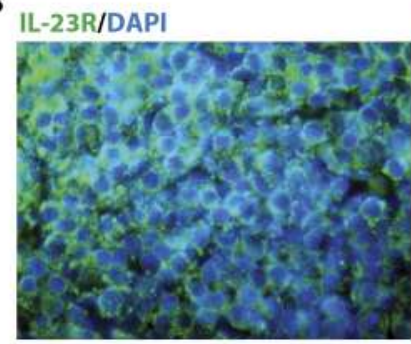

IL-12Rß1/DAPI

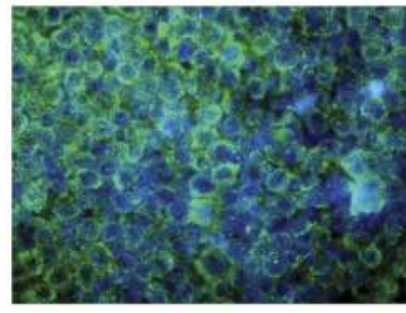

IL-23/DAPI

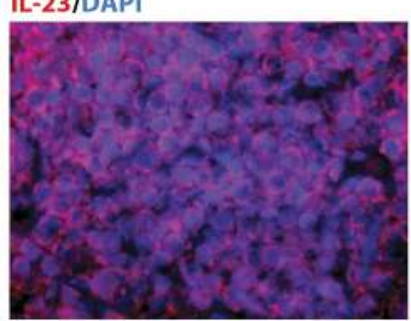

IL-23/DAPI
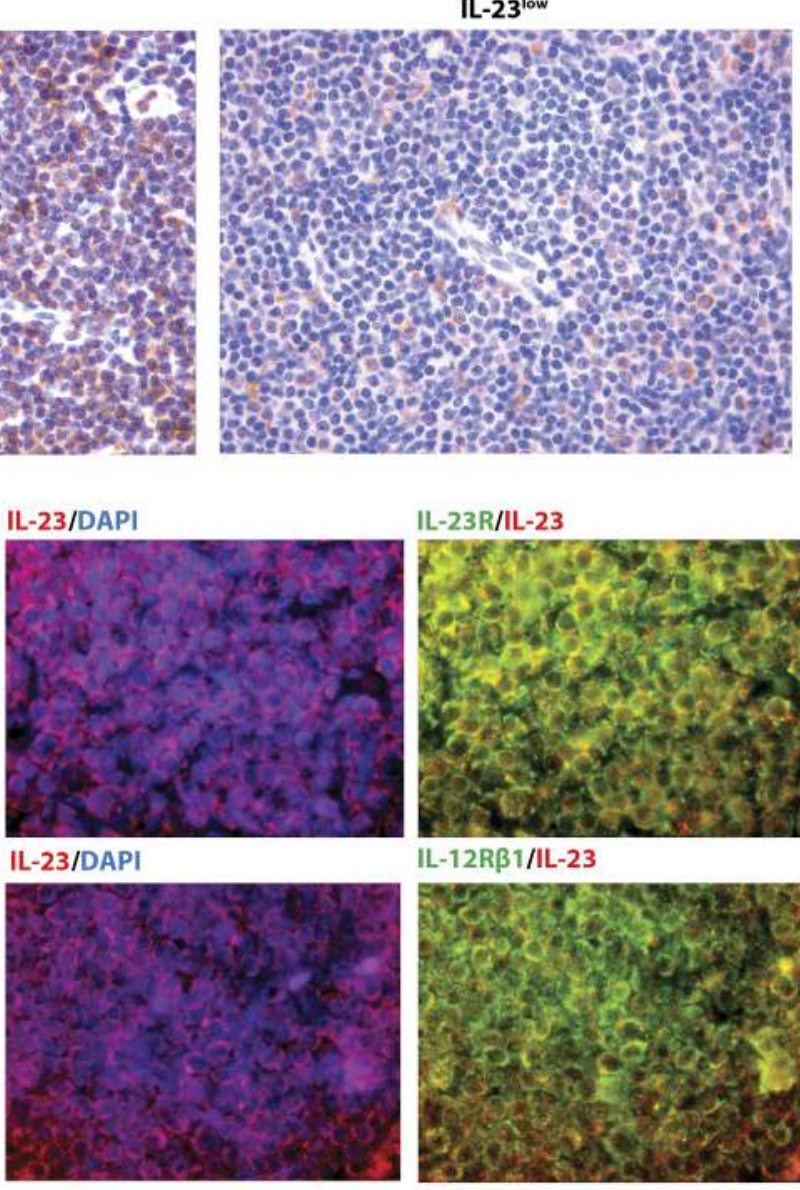

IL-23R/IL-23

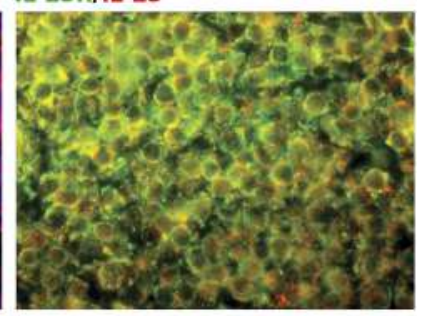

IL-12Rß1/IL-23

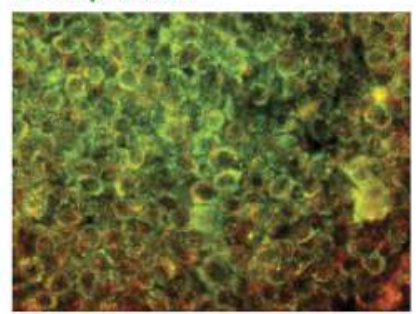

C

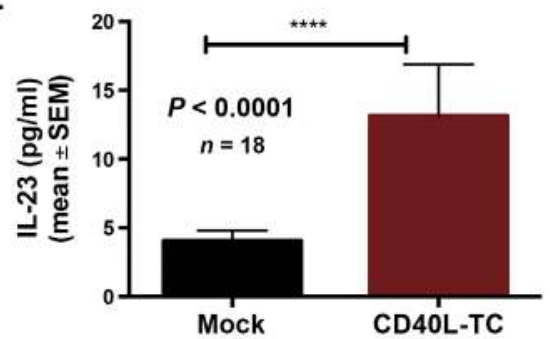

CLL cells cultured with
D

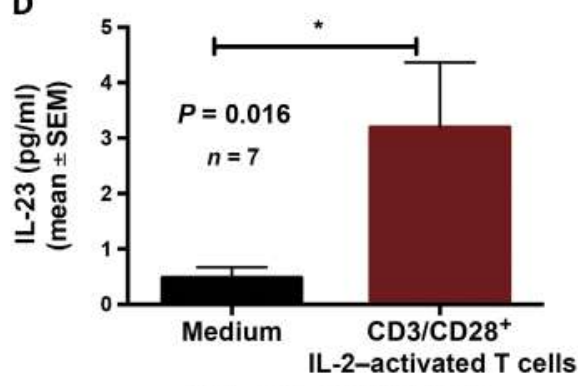

CLL cells cultured with

Fig. 4. IL-23 production by CLL clones. (A) Immunohistochemistry (IHC) evaluation of two representative cases of CLL lymph node specimens (of the 16 examined) producing higher $(n=6)$ or lower $(n=10)$ levels of IL-23 (magnification, $\times 200$ ). (B) Double-marker IF and confocal microscopy analysis of IL-23R chain and IL-23 or IL-12Rß1 chain and IL-23 or DAPI of a representative CLL lymph node displaying IL-23R ${ }^{\text {high }}$ chain (of six analyzed) showing production of IL-23 cytokine by IL-23R complex-expressing cells (magnification, $\times 200$ ). Microphotographs in (A) and (B) are representative of analyses of at least 10 microscopic fields performed on each lymph node sample. (C) IL-23 production in supernatants of cells from $18 \mathrm{CLL}$ cases cultured in the presence of CD40L-TC or control (Mock) fibroblasts. (D) IL-23 production by CLL cells induced by contact with activated autologous T cells. PBMCs from seven CLL cases were cultured in the presence of CD3/CD28 beads and IL-2 or in medium alone for 120 hours. At the end of this period, CLL cells were depleted of T cells by negative selection and placed in culture for an additional 24 hours before measuring IL-23 concentrations (in picograms per milliliter) in the supernatant. $P$ values of the difference between stimulated CLL cells and controls are indicated (Wilcoxon test). Asterisks indicate statistically significant $P$ values $(P<0.05)$.

Coculture with the HS5 stromal cell line enhanced IL-23R complex expression by CLL cells, although the observed increase was lower than that obtained by cocultures with CD40L-TC or with activated T cells.
In contrast, there was no significant upregulation of the IL-23R complex after coculture of CLL cells with NLCs. Consistent with this is the observation that HS5 stromal cells and NLCs were CD40Lnegative [fig. S5 and (30)]. However, when PBMCs of CLL patients, rather than highly purified CLL cells, were cocultured with NLCs, there was an up-regulation in the expression of the IL-23R complex (fig. S6). As expected from previous data (30-32), there was an inhibition of spontaneous CLL cell apoptosis in both culture conditions. The data are summarized in fig. S7.

No significant release of IL-23 cytokine (mean \pm SEM) was detected in the culture supernatants of CLL cells cultured with medium or with autologous NLC for 7 days $(n=4$ CLL cases, $6.44 \pm 0 \mathrm{pg} / \mathrm{ml}$ versus $1.46 \pm 0 \mathrm{pg} / \mathrm{ml}$, respectively) or for CLL cells cultured with medium or with HS5 stromal cells for 72 hours $(n=8$ CLL cases, $6 \pm 1.2 \mathrm{pg} / \mathrm{ml}$ versus $3.6 \pm 1.6 \mathrm{pg} / \mathrm{ml}$, respectively), which led us to the conclusion that the IL-23R complex/IL-23 loop was not activated under these culture conditions.

We also investigated whether BCR stimulation of purified CLL cells could induce IL-23R complex expression. Exposure to insolubilized anti- $\mu$ antibody $(\mathrm{G} \alpha \mu-\mathrm{Ab})$ failed to induce IL-23R complex expression even in the presence of IL-4 [fig. S8, A and B, and (33)]. This treatment induced phosphorylation of Bruton's tyrosine kinase (pBTK) and increased cell viability in culture (fig. S8B).

We also investigated whether the $\mathrm{BCR}$ pathway was involved when CLL cells were induced to express the IL-23R complex by contact with CD40L-TC. To this end, purified CLL cells were incubated with the BTK inhibitor ibrutinib $(1 \mu \mathrm{M}) 1$ hour before coculturing with CD40L-TC or mock cells (fig. S8). After ibrutinib exposure, the IL-23R complex was still detectable, although on a smaller percentage of cells (fig. S8C). This treatment caused inhibition of pBTK and decreased cell viability, as shown in fig. S8 (D and E).

\section{IL-23 acts as a growth factor for CLL cells}

Next, we investigated whether IL-23 could facilitate survival and expansion of activated CLL cells in culture. PBMCs from CLL patients were exposed to $\mathrm{CD} 3 / \mathrm{CD} 28$ beads for 120 hours in culture, and the CLL cells were subsequently separated from $\mathrm{T}$ cells by negative selection using an EasySep Human B Cell Enrichment Kit and then recultured in the 
presence or absence of IL-23 for an additional 48 hours. A significantly increased viability and a higher Ki67 expression were observed in IL-23-treated CLL cells compared to control cells not exposed to IL-23 (Fig. 5, A and B). Addition of IL-23 neutralizing $\mathrm{mAb}(\alpha \mathrm{IL}-23 \mathrm{p} 19)$ to CLL cultured alone resulted in decreased cell viability and proliferation, indicating that there was a production of IL-23 in the culture acting in an autocrine/paracrine manner. This effect of $\alpha$ IL-23p19 was largely inhibited by the addition of exogenous IL-23, indicating that the antibody was indeed neutralizing the endogenously produced IL-23. In a subsequent series of experiments, purified CLL cells were activated by coculturing with CD40L-TC for 72 hours and then exposed to small interfering RNAs (siRNAs) specific for IL-23A mRNA and IL-23R mRNA or to negative control siRNAs (see Supplementary Materials and Methods). As apparent from fig. S9, which shows the results of one representative experiment of three carried out on different cases, treatment with the appropriate siRNAs, but not with the control siRNAs, caused inhibition of IL-23 and IL-23R mRNA production, inhibition of IL-23R expression, and reduction of cell viability and proliferation.

Different intracellular kinase inhibitors were added to purified CLL cells cultured with IL-23 after a preactivation step with stimulated autologous T cells. As shown in Fig. 5 (C and D), ibrutinib treatment had virtually no effect on cell viability and proliferation, whereas tofacitinib [a pan-Janus kinase (JAK) inhibitor] and ruxolitinib (a specific JAK1/2 inhibitor) were effective in decreasing cell viability and particularly cell proliferation. The inhibitory kinase effect was also exerted in the presence of exogenous IL-23.

We further investigated the presence of phosphorylated signal transducer and activator of transcription 3 (pSTAT3) and pBTK proteins after exposure of activated CLL cells to IL-23. pSTAT3 (but not pBTK) increased after cell exposure to IL-23 (Fig. 5E), and phosphorylation persisted in the cultured cells up to 48 hours (Fig. 5H). BTK was

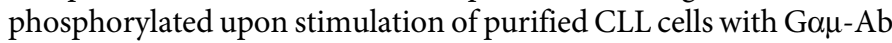
or $\mathrm{G} \alpha \delta-\mathrm{Ab}$ (anti- $\delta$ antibody) or with a combination thereof, providing an effective positive control (Fig. 5F). The preactivation step of CLL cells in culture with activated T cells caused an up-regulation of pSTAT3, which was rather heterogeneous and case-dependent (typical examples of this phenomenon are shown fig. S10). This pSTAT3 up-regulation produced a sort of background noise in the cells cultured in the absence of IL-23, which is visible in Fig. 5 ( $\mathrm{G}$ and $\mathrm{I}$ ). However, the levels of pSTAT3 in the preactivated cell cultures when reexposed to IL-23 were consistently higher (Fig. 5, G and I). Furthermore, there was a marked inhibition of pSTAT3 detected by flow cytometry when preactivated CLL cells were cultured with IL-23 in the presence tofacitinib and ruxolitinib (Fig. 5, J and $\mathrm{K})$. Under these conditions, ibrutinib was ineffective on pSTAT3 signals, although it had some effect on pBTK. Collectively, these data support the notion that the JAK/STAT pathway was primarily involved in IL-23 signaling to CLL cells and in sustaining cell proliferation in vitro.

\section{IL-23R complex expression is up-regulated in CLL cells growing in NSG mice}

Next, we investigated whether the costimulatory signals inducing up-regulation of the IL-23R complex by CLL cell in vitro could be functionally recapitulated by tissue microenvironment signals in vivo. PBMCs from an IL-23R ${ }^{\text {low }}$ CLL case (PM608; Fig. 6A) were inoculated into NOD/Shi-scid, $\gamma$ cnull (NSG) mice (34). Eight weeks after cell injection, mice were sacrificed, and spleen and liver were analyzed for CLL cell infiltration (Fig. 6, B to D). Neoplastic cell infiltrates, highlighted by human CD20 immunoreactivity, were found in association with patient-derived $\mathrm{T}$ cells, identified mainly as human $\mathrm{CD}^{+}$and, to a lesser extent, human $\mathrm{CD}^{+}$cells (Fig. 6B). Moreover, within splenic and hepatic infiltrates, CLL cells showed a high proliferative rate, as suggested by double-marker immunostaining for human CD20 and Ki67 (Fig. 6C). CD20-positive xenografted CLL cells, which expressed low levels of both IL-23R and IL-12R $\beta 1$ chains at baseline, showed consistent up-regulation of both chains of the IL-23R complex within murine splenic and hepatic infiltrates (Fig. 6C). Coexpression of IL-23R and IL-12R $\beta 1$ chains was confirmed by flow cytometry (Fig. 6D). Notably, double-marker confocal microscopy analysis and flow cytometry showed that CLL cells also synthesized IL-23 within murine tissue infiltrates (Fig. 6, E and F). Similar immunohistochemical patterns of staining for IL-23R complex were observed in three additional xenografting experiments using PBMCs derived from three CLL cases with different baseline levels of IL-23R expression [ZC0010 (8.1\%), MG0248 (19.5\%), and CD0310 (23.7\%); fig. S11]. Table S4 reports the features of the cells from different CLL cases $(n=22)$ used throughout this study; immunohistochemistry (IHC) patterns of CLL cell infiltration similar to those described above were observed in mice xenografted with CLL cells from different cases and with different characteristics. Engraftment was measured by determining the IHC index, derived from the combination of size and numbers of CD20-positive follicles in the spleen [see (35), the Supplementary Materials, and Materials and Methods]. Engraftment capacities of the different CLL clones in NSG mice were similar regardless of whether they were classified as IL-23R ${ }^{\text {high }}$ or IL-23R ${ }^{\text {low }}$.

\section{Interruption of the IL-23R/IL-23 loop has therapeutic effects in vivo}

We next investigated the in vivo effect of $\alpha$ IL-23p19 mAb-based treatment (36). Eighteen NSG mice were xenografted with circulating PBMCs from three different CLL cases (PA0146, GA0626, and GE1-BA101, which were xenografted in 4, 4, and 10 mice, respectively). After 4 to 6 weeks, all mice showed leukemia engraftment, based on the flow cytometry detection of circulating human $\mathrm{CD} 45^{+} \mathrm{CD} 19^{+} \mathrm{CD} 5^{+}$cells. At this point, mice were treated either with one dose of an anti-human IL-23p19 mAb or with the isotype control antibody in each of the days indicated in Fig. 7A. The amount of CLL cells detected in different compartments, evaluated 3 days after the last treatment, was significantly higher in mice treated with the isotype control compared with mice treated with the $\alpha \mathrm{IL}$ $23 \mathrm{p} 19 \mathrm{mAb}$, irrespective of tissues where the analysis was performed (Fig. 7B). Moreover, IHC analysis of human CD20-expressing CLL cells showed that mice treated with the neutralizing $\alpha$ IL-23p19 mAb were virtually free of disease infiltration and presented a few cells containing human IL-23 compared to controls (Fig. 7, C and D). In the spleen of mice freed of the disease after treatment, foci of stromal remodeling indicative of former parenchymal infiltration could be detected morphologically (Fig. 7, C and D). Notably, mice treated with $\alpha$ IL-23p19 mAb showed increased apoptosis in CLL cells (Fig. 7, $\mathrm{E}$ and F) as compared with isotype control-treated mice. Consistently, in mice treated with $\alpha \mathrm{IL}-23 \mathrm{p} 19 \mathrm{mAb}$, there was a decrease of Ki67-positive CLL cells as assessed by double-marker IF and flow cytometry analyses on spleen infiltrates (Fig. 7, G to I). Notably, molecular testing for the specific BCR rearrangement of the CLL clone 
Fig. 5. Functional analysis of IL-23 signaling in CLL cells. (A) Flow cytometry determination of viable cells [annexin V/propidium iodide (PI)negative cells] or of (B) Ki67-positive CLL cells. PBMCs from CLL patients were cultured with $\mathrm{CD} 3 / \mathrm{CD} 28$ beads +IL-2 (120 hours). Subsequently, CLL cells were purified by negative selection and recultured for 48 hours in the presence or absence of IL-23 $(100 \mathrm{ng} / \mathrm{ml})$ or of IL-23 neutralizing monoclonal antibody (mAb) ( $\alpha$ IL23p19) in the indicated combinations. (C and D) PBMCs from CLL patients were cultured with $C D 3 / C D 28$ beads + IL-2 for 120 hoursas in (A) and (B).CLL cells were subsequently purified by negative selection and recultured in the presence of the indicated kinase inhibitors with or without IL-23. Cell viability and Ki67 expression were determined after a 48-hour culture. Each dot represents a test on a different CLL case. Mean \pm SEM are given. Statistical analysis was carried out using Wilcoxon ( $A$ to $C$ ) or Mann-Whitney $U$ tests (D). Asterisks indicate statistically significant $P$ values $(P<0.05)$. (E) Immunoblotting analysis of signal transducer and activator of transcription 3 phosphorylation (pSTAT3) and Bruton's tyrosine kinase phosphorylation (pBTK) in purified CLL cells (from case RD0468; 52\% IL-23R-positive cells) activated with T cells as in (A), purified and stimulated at $37^{\circ} \mathrm{C}$ with IL-23 for the indicated times. (F) Phosphorylation of BTK and STAT3 was assessed in freshly isolated CLL cells after exposure to anti- $\mu$ antibody ( $G \alpha \mu-A b)$, anti- $\delta$ antibody $(G \alpha \delta$ $\mathrm{Ab})$, or a combination of both, at $37^{\circ} \mathrm{C}$ for 5 min. CTR, control. (G) Summary of data from five tests of STAT3 phosphorylation on different CLL cases: Data are presented as pSTAT3/ total STAT3 (tSTAT3) ratio after a 10-min and 30-min incubation with IL-23. (H) CLL cells (from case AM609; $53 \%$ IL-23R-positive cells) were induced to express the IL-23R complex as in (A), purified and exposed to IL-23 or medium alone for the indicated times, and studied for the presence of PSTAT3 by flow cytometry (right). Left: Results obtained in CLL cells for which the preactivation step was omitted (PBMCs from CLL patients were cultured without CD3/

A

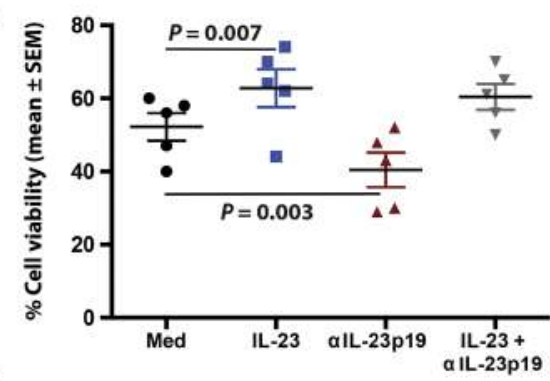

C

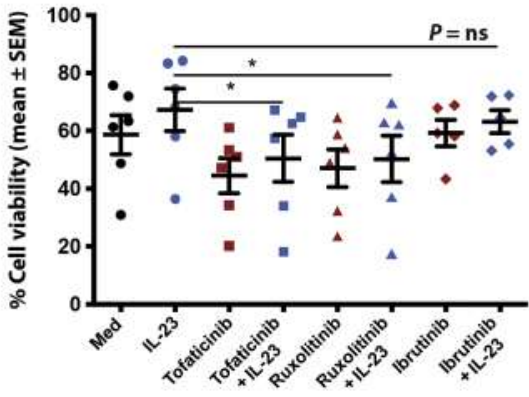

$\mathbf{E}$

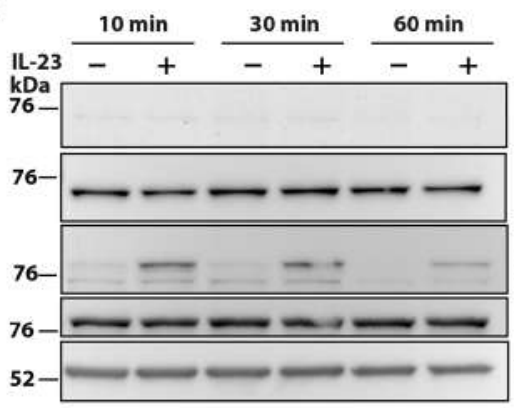

B

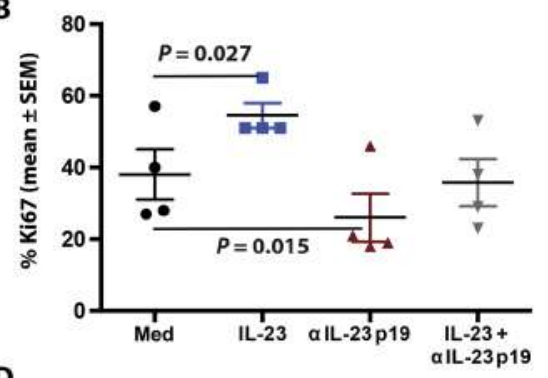

D

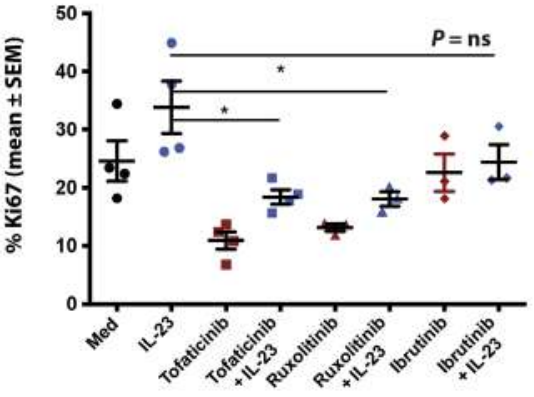

F

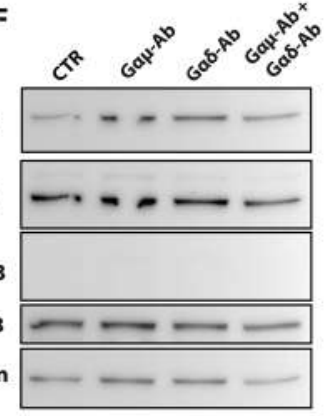

G

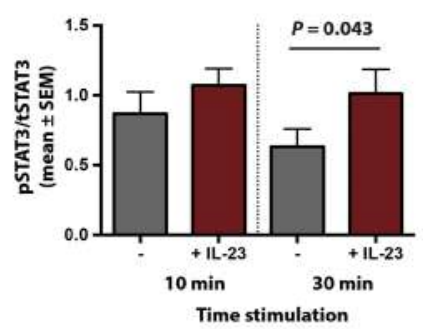

H
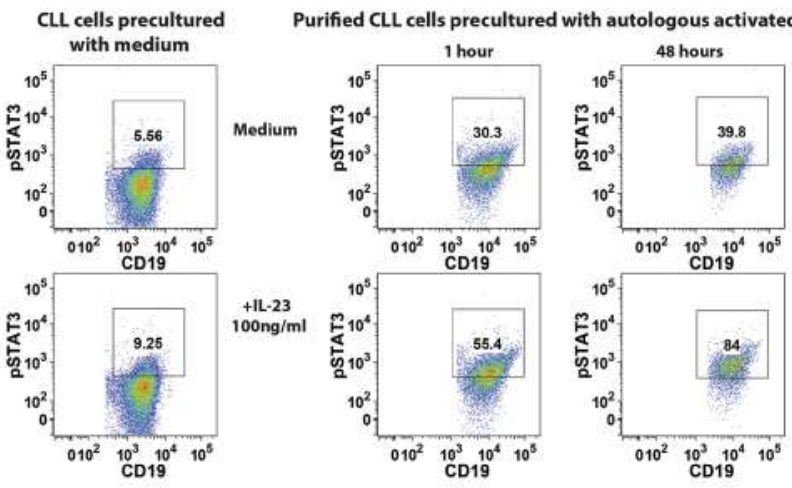

J

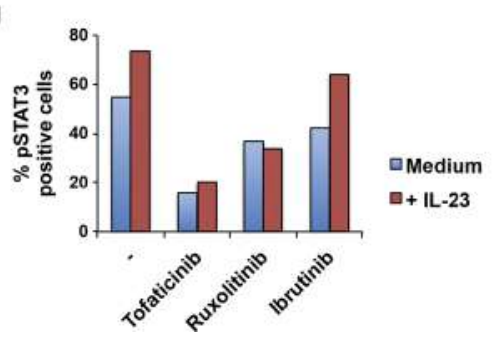

K

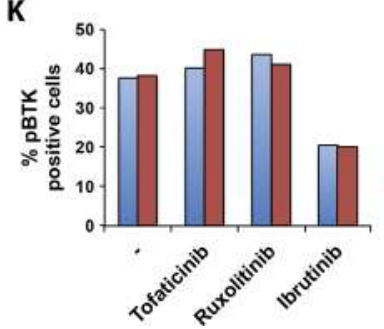

I

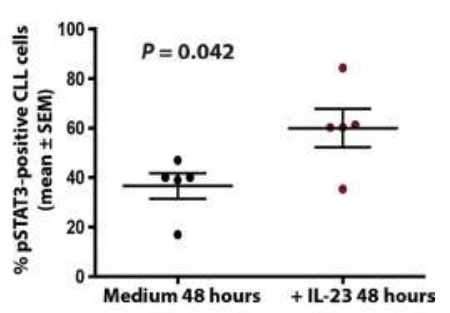

CD28 beads; CLL cells were purified and then exposed to IL-23 or medium alone for 1 hour). The degree of pSTAT3 was evaluated on viable cells gated as in Fig. $3 \mathrm{~A}$ and as detailed in fig. S1.CD19 expression was also detected to verify the purity of the CLL cell isolation. (I) Summary of data on PSTAT3 induction (determined by flow cytometry) after a 48-hour exposure to IL-23 in activated and purified CLL cells [as in (A)] from five different CLL cases. (J and K) CLL cells from case GE1-CC45 (36\% IL-23R-positive cells) were activated and purified as in (A) and cultured in the presence or absence of the indicated inhibitors for 48 hours, and pSTAT3-positive $(J)$ or pBTK-positive (K) cells were measured by flow cytometry. 
A
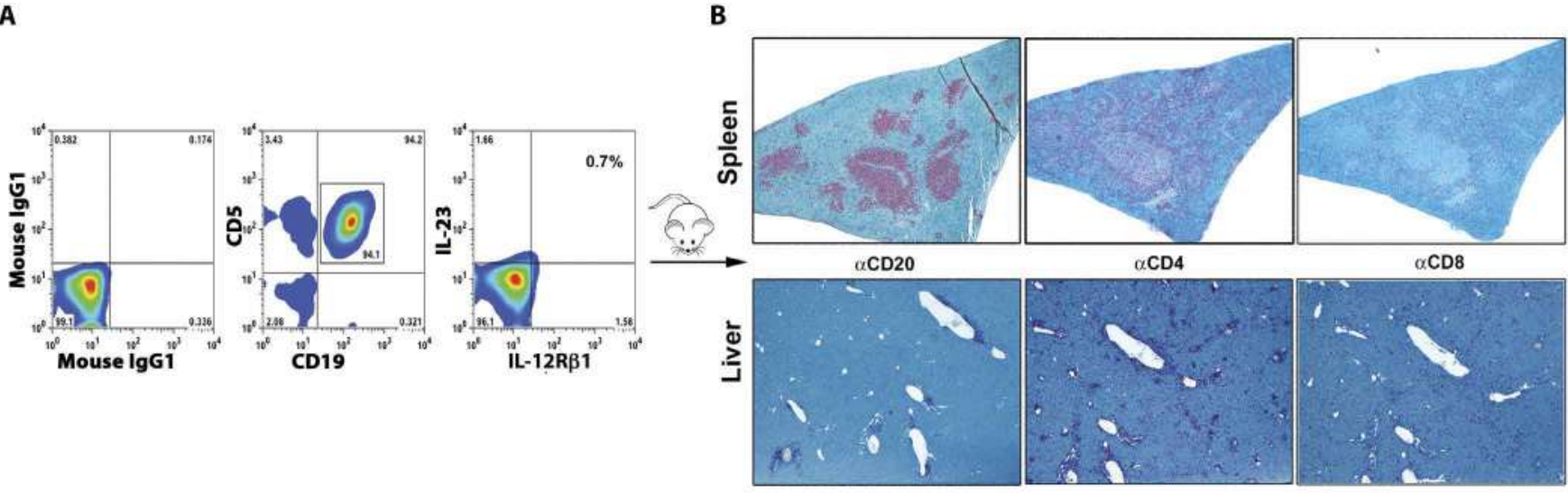

$\alpha \mathrm{CD} 4$
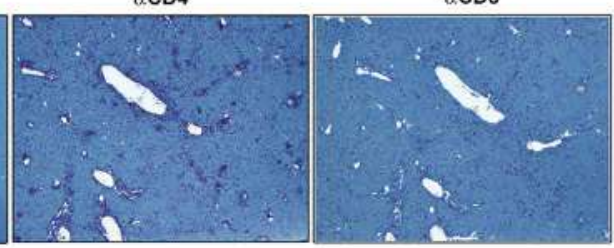

D
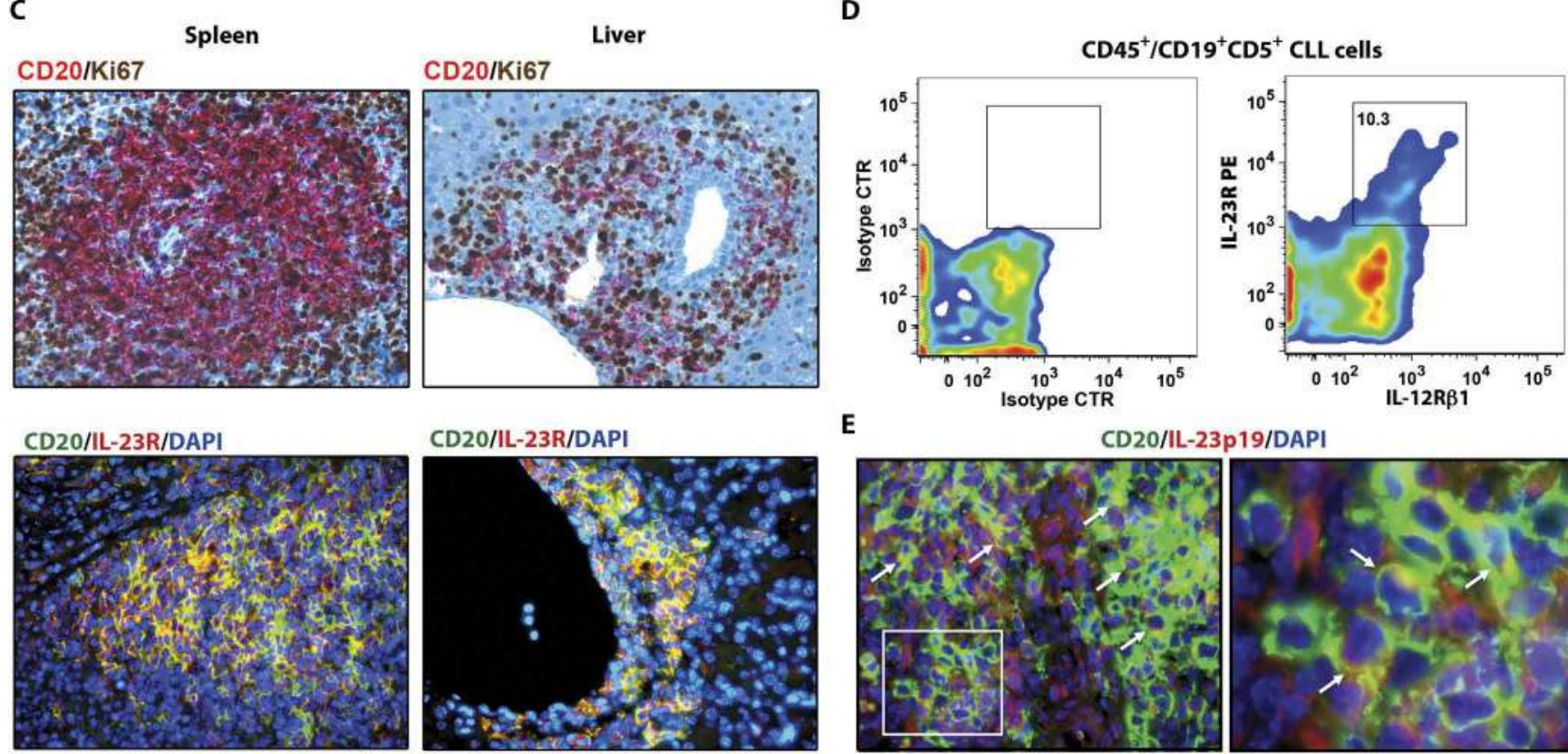

E
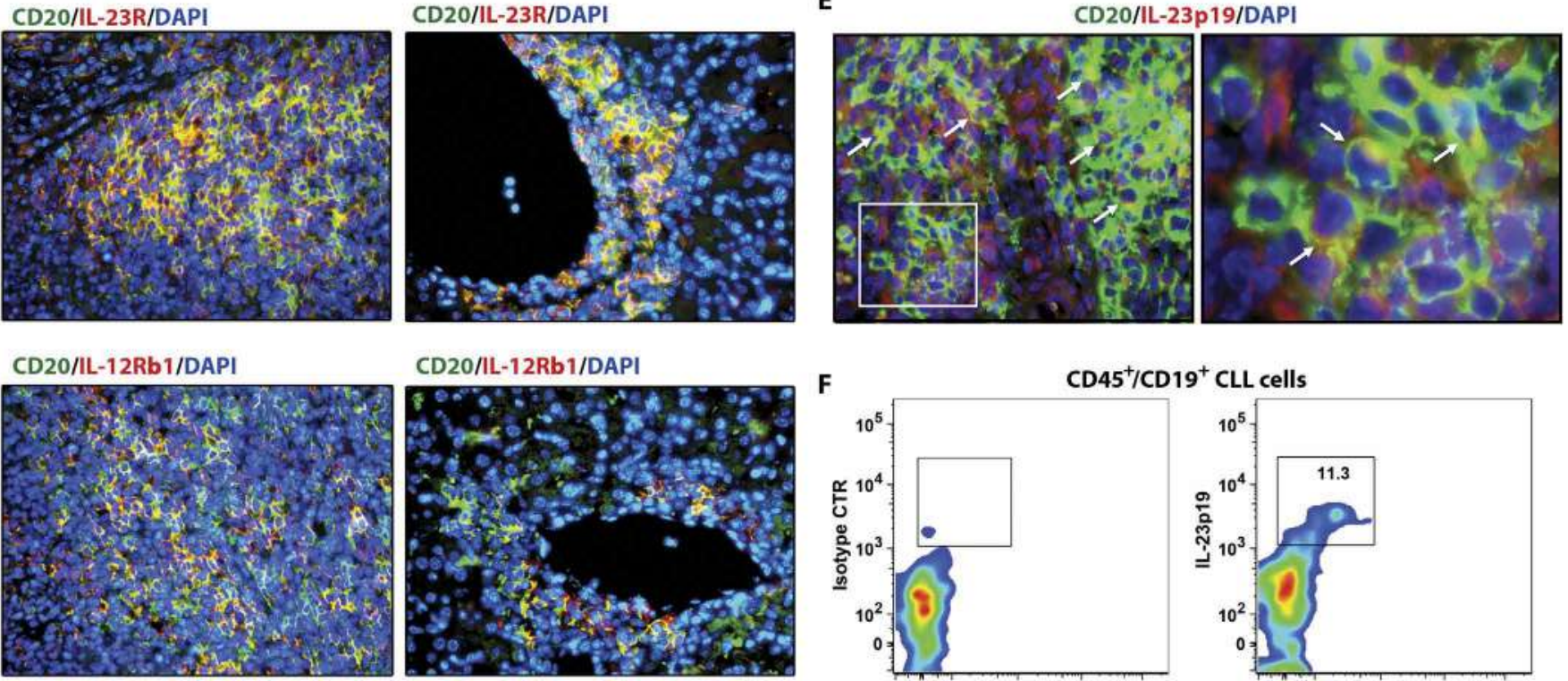

$\mathbf{F}$

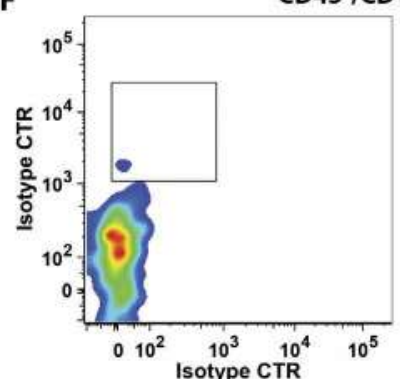

Fig. 6. NSG mice model engrafted with CLL cells. A total of $50 \times 10^{6} \mathrm{PBMC}$ cells from case PM608 were injected into three NOD/Shi-scid, $\gamma \mathrm{cnull}$ (NSG) mice intravenously. Mice were sacrificed and analyzed 4 weeks after the inoculum. (A) Flow cytometry analysis shows that the injected cells were IL-23R ${ }^{\text {low }}(6.3 \%$ positive cells). (B) IHC analysis of tissue slices from engrafted mice showing spleen (top) and liver (bottom) infiltration by CLL cells stained by the indicated anti-human mAb (magnification, $\times 40$ ). (C) IHC (top, magnification, $\times 400$ ) and IF (middle and bottom, magnification, $\times 40$ ) staining of paraffin-embedded tissue slice sections showing expression of IL-23R chains in areas characterized by cell proliferation (Ki67 ${ }^{+}$cells). (D) Flow cytometry analysis of the IL-23R complex in CLL cells in mouse spleen. PE, phycoerythrin. (E) Confocal microscopy image of the mouse spleen. The arrows indicate neoplastic CLL cells (human CD20 ) producing human IL-23 (IL-23p19 ) [magnifications, $\times 200$ (left) and $\times 630$ (right)]. (F) IL-23 chains in xenografted CLL cells measured by flow cytometry. Human IL-23 chains were detected by intracellular staining with $\alpha$ IL-23p19 and $\alpha \mathrm{lL}-12 / \mathrm{IL}-23 \mathrm{p} 40$ antibodies on gated human CD45 $\mathrm{CD} 19^{+} \mathrm{CLL}$ cells. Microphotographs are representative of analyses on at least 10 for high-power magnification ( $\times 200$ to $\times 630)$ microscopic fields performed on each mouse spleen tissue sample. 
Fig.7.Treatment with neutralizing IL-23 antibody (alL-23p19) inhibits CLL growth and proliferation in the NSG mouse model.

(A) Treatment scheme of oll-23p19 or isotype CTRmAb in NSG mice. Mice were injected with $50 \times 10^{6} \mathrm{CLL}$ cells previously stimulated with autologous activated T cells. After 4 to 6 weeks, blood samples were evaluated for the presence of circulating leukemic cells by flow cytometry before treatment with four doses of $\alpha$ LL-23p19 or isotype CTR mAbs every 2 days. At the end of the experiments, mice were sacrificed, and cell suspensions from the spleen, liver, bone marrow (BM), and peripheral blood were analyzed by flow cytometry for the percentage of neoplastic B cells (human $\mathrm{CD}^{+} \mathrm{CD} 19^{+}$cells / total human $\mathrm{CD}^{2} 5^{+}$cells).

(B) The mean and SEM of 18 mice injected with CLL cells from three different cases (PA0146, GC0626, and GE1-BA101) are shown (Wilcoxon test). (C) Lowmagnification image (top) of longitudinal sections of paraffin-embedded mouse spleen (CLL PA0146) doublestained for CD20 and Ki67. Spleen from mouse treated with isotype CTR (left) or all-23p19 (right) mAb. Anal$y s i s$ at higher magnification $(\times 400)$ is shown (bottom). (D) IHC analysis of IL-23p19 in spleens of mice treated as indicated in (A). (E and F) Demonstration of apoptotic neoplastic cells in both treated and control mice spleen by CD45/CD19/CD5/ annexin $V$ staining and flow cytometry. (G) Demonstration of Ki67-positive cycling cells by flow cytometry and (H) by confocal microscopy (magnification, $\times 200$ ) in spleens of isotype CTR (top

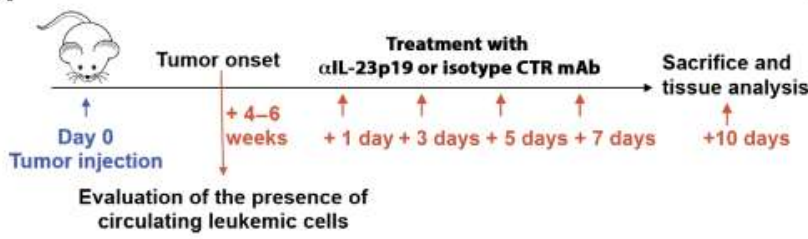

C
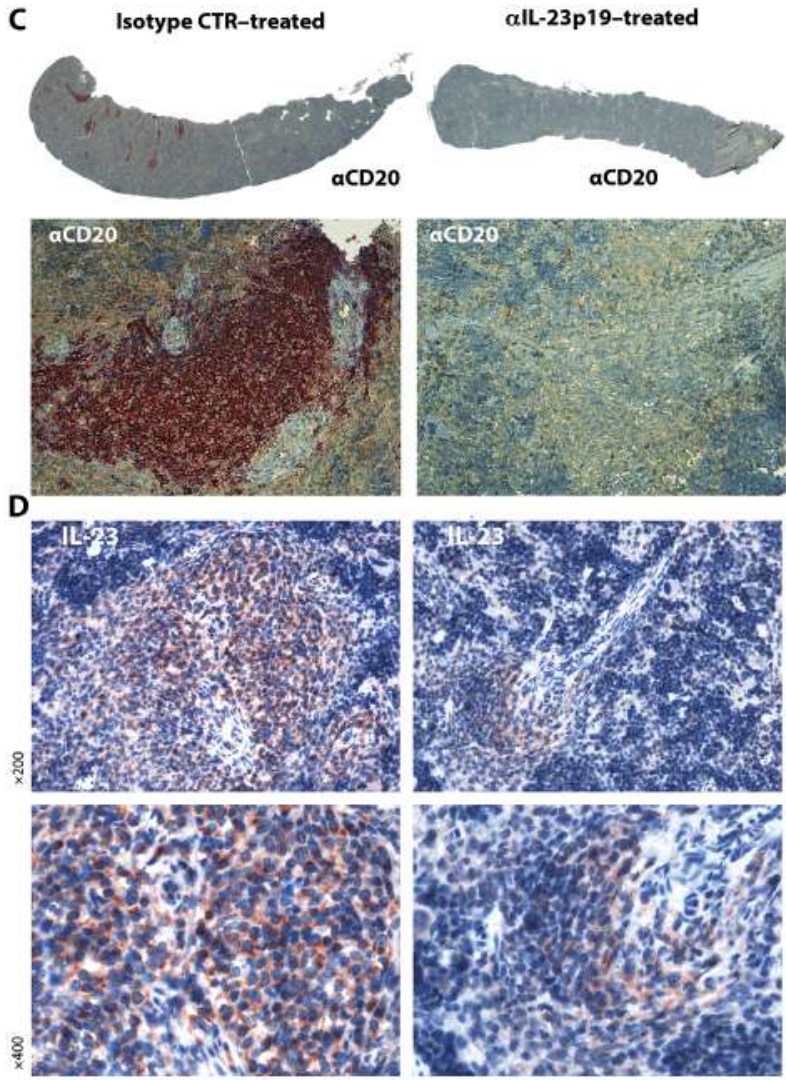

$\mathbf{G}$

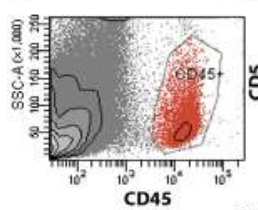

Mice treated with isotype CTR

H
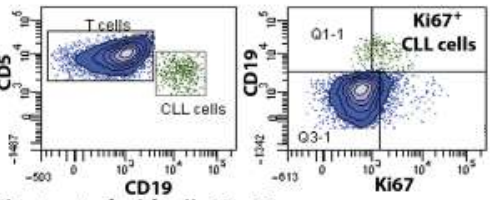

Mice treated with $\alpha$ IL-23p19
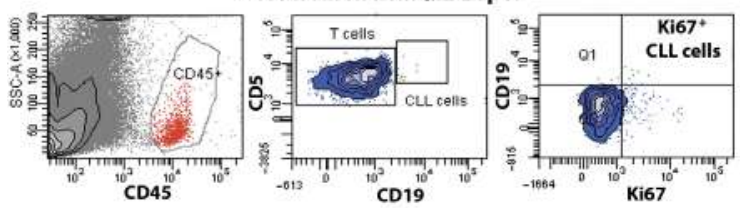

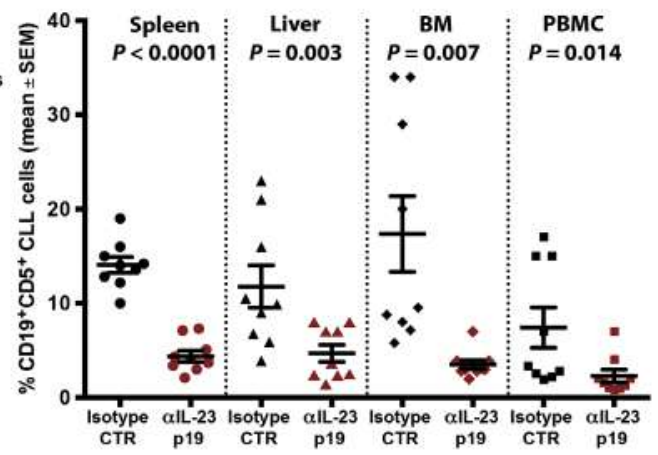

E

Mice treated

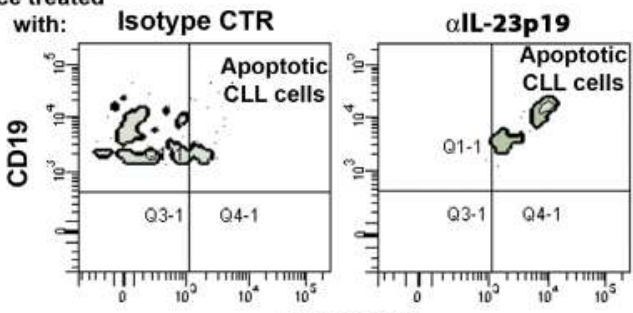

Annexin V

F
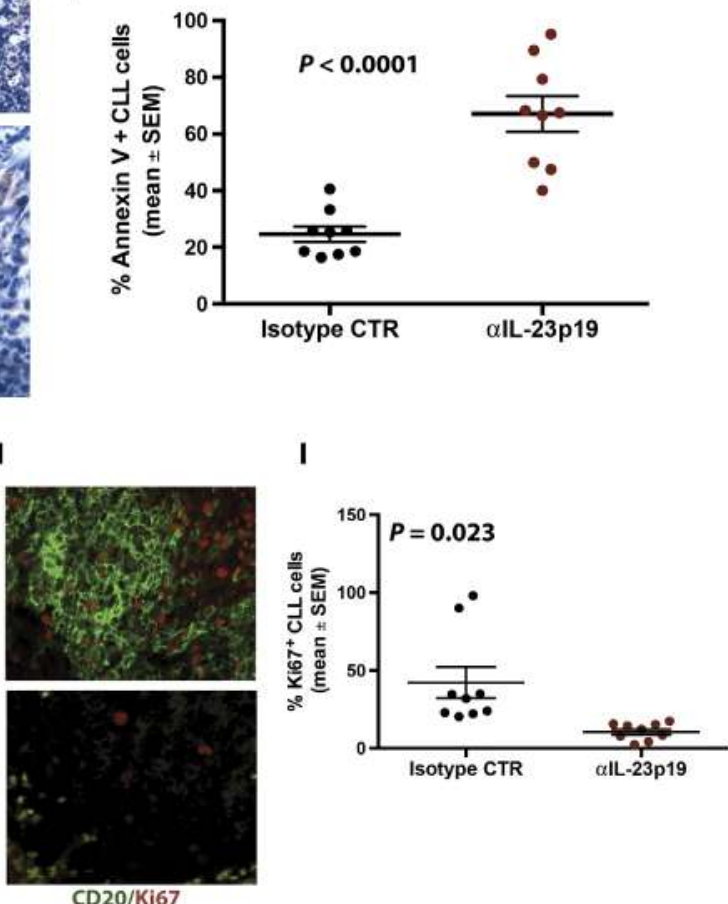

CD20/Ki67 $(\times 200, \times 400)$ microscopic fields performed on each mouse tissue sample. The scatter dot plots in (B), (F), and (I) show data for each mouse, and mean values are calculated for each treatment mice group; statistical comparisons were carried out by Wilcoxon test. SSC-A, side scatter area.

of the donor patient was identified in different compartments of control antibody-treated mice and was not detected in mice achieving a complete remission as determined by flow cytometry evalua- tion (fig. S12). The striking effect of $\alpha \mathrm{IL}-23 \mathrm{p} 19 \mathrm{mAb}$ treatment does not appear to be attributable to opsonization of CLL cells by $\alpha$ IL23 p19 mAb, which, in principle, could recognize the IL-23 bound 
to activated CLL cells. The cells so opsonized could be subsequently killed by antibody-dependent cell-mediated cytotoxicity or complement activation. This conclusion stems from the observation of very few human CD16-positive cells in the proximity or within leukemic nodules in NSG mice (fig. S13A). Moreover, CLL cells activated in vitro by coculture with activated $\mathrm{T}$ cells and exposed to IL-23 failed to bind $\alpha \mathrm{IL}-23 \mathrm{p} 19 \mathrm{mAb}$ (fig. S13B) and to fix complement (fig. S13C).

In an independent set of in vivo experiments, we investigated whether $\alpha$ IL-23p19 mAb treatment could be effective in achieving a durable response in mice with rapidly progressive disease. Given that experiments in mice could not be prolonged for longer than 9 weeks because of possible excessive animal suffering, the experiments were designed as follows: 12 mice were injected with a higher number of PBMCs $\left(100 \times 10^{6}\right.$ cells per mouse) from CLL case SD36 (6 mice) or CLL case GE2-RL201 (6 mice) to obtain a more rapid engraftment with a high leukemic burden. Two weeks after cell injection, the average percentage of circulating leukemic cells (human $\mathrm{CD} 45^{+} \mathrm{CD} 19^{+} \mathrm{CD} 5^{+}$ cells) in the 12 mice was $73.4 \pm 2.6 \%$. At this time point, therapy was administered with the same schedule described above (Fig. 7A): Six mice received $\alpha \mathrm{IL}-23 \mathrm{p} 19 \mathrm{mAb}$ (4 doses) and the other six received the isotype control $\mathrm{mAb}$. Three weeks from the last $\mathrm{mAb}$ dose, mice were sacrificed, and IHC on spleen tissue sections was carried out (Fig. 8, A and B). CLL cells were also measured in the spleen, liver, bone marrow, and PBMCs by flow cytometry (Fig. 8C). The administration of a high number of leukemic cells caused the appearance of larger and more numerous infiltration foci in the mice spleen parenchyma, as observed by IHC for human CD20 staining. These foci were substantially reduced in number and size after $\alpha$ IL-23p19 $\mathrm{mAb}$ treatment. The actual relation of the infiltration foci with the CLL clones was documented by IGHV gene rearrangement analysis (Fig. 8, A and B, insets). The number of CLL cells infiltrating the different tissues was largely reduced in the $\alpha \mathrm{IL}-23 \mathrm{p} 19 \mathrm{mAb}$-treated mice compared to controls at all sites tested by flow cytometry $(P=$ 0.03, Wilcoxon test) (Fig. 8C).

\section{DISCUSSION}

We have identified an autocrine/paracrine loop represented by the IL-23 complex expression and IL-23 production necessary for the clonal expansion of CLL cells (fig. S14). Inhibition of this loop with the appropriate $\mathrm{mAb}$ resulted in impaired viability and incapacity for CLL cell proliferation in vitro and prevented expansion of the leukemic clones in NSG mice with a prolonged remission of the disease. Therefore, the IL-23R/IL-23 axis may represent a suitable target for CLL treatment.

The expression of the IL-23R complex and particularly of the "limiting" IL-12R $\beta 1$ chain was dependent on interactions with microenvironmental elements, as demonstrated by in vitro studies and corroborated by in situ observations on LN tissue sections showing the proximity between activated, IL-23R complex-expressing CLL cells with stromal macrophages and other $\mathrm{CD} 40 \mathrm{~L}^{+}$cells. These data are also in line with observations in NSG mice, indicating that activated/proliferating $\mathrm{Ki}^{+} 7^{+} \mathrm{CD} 38^{+} \mathrm{CLL}$ cells were also capable of expressing the IL-23R complex in vivo.

Expression of the IL-23R complex appears to be a multistep process, characterized by the initial expression of the IL-23R and, subsequently, by that of the IL-12R $\beta 1$. The progressive expression of these structures may be regulated by the cell activation status. CLL clones appear to be frozen at two particular stages: no receptor expression (IL-23R ${ }^{\text {low }} \mathrm{CLL}$ ) or expression of the IL-23R only (IL-23R $\mathrm{h}^{\text {high }}$ CLL). The IL-23R $\mathrm{R}^{\text {low }}$ and IL-23R $\mathrm{R}^{\text {high }}$ phenotypes also distinguish two patient groups with different clinical features. Higher activation of IL-23R ${ }^{\text {high }}$ CLL clones may in part explain the more aggressive disease progression. Whether this stepwise process of IL-23R complex expression also characterizes the activation process of normal B cells and their response to IL-23 is presently unknown. However, the hypothesis that CLL cells have a genetic defect, either germ line or somatic, which prevents a complete IL-23R complex expression (37), was ruled out by a number of observations, including the fact that IL-23R complex expression can be induced on CLL cells from both (IL-23R $\mathrm{R}^{\text {high }}$ and IL-23R $\mathrm{R}^{\text {low }}$ ) groups of patients in vitro and in NSG mice and that substantial expression of IL-23R complex was observed in the NK cells and T cells of the same CLL patients.

The IL-23R complex/IL-23 loop was not induced by coculturing CLL cells with stromal cells or NLCs. Because both cell types do not express CD40L, these observations stress the requirement for a CD40L/ CD40 interaction in the activation of this autocrine/paracrine loop. Notably, the failure of NLCs and stromal cells to activate this loop was observed only when highly purified CLL cells (and not total PBMCs from the patients) were used in the coculture systems, indicating that the few activated $\mathrm{T}$ cells or other CD40L-expressing cells remaining in the PBMCs were sufficient to sustain IL-23 production and IL-23R complex expression. The involvement of the CD40/CD40L interactions is also supported by the observation that BCR stimulation was unable to activate the IL-23R complex/IL-23 loop, even in the presence of IL-4 $(33,38)$, although BCR-derived signals may exert a regulatory role. For example, ibrutinib caused some inhibition of the IL23R complex induction in vitro in CLL cells activated via CD40L stimulation. Because there was a concomitant diminution of cell viability, this was likely related to the inhibition of the trophic effect normally exerted by BCR on B cells $(39,40)$. This inhibition of BCRdelivered trophic signals is likely to be responsible for most of the reduction of CLL cell clonal expansion caused by ibrutinib in NSG mice (41).

Signals of the IL-23R complex after binding to IL-23 are delivered via STAT3, as documented by the observation that exposure of activated CLL cells to IL-23 caused pSTAT3 increase as in previous studies $(22,42)$ and that this pathway was susceptible to the effect of JAK/ STAT inhibitors and was resistant to ibrutinib. Therefore, the JAK/ STAT pathway may represent an additional therapeutic target for CLL, independent of the BCR pathway.

IL-23 released by CLL cells may affect the patient T cell subset population composition and function, given its effects on $\mathrm{T}$ cells (fig. S14) (43). These considerations may help explain abnormalities in T cell composition reported both in patients and in experimental animals with CLL-like disease (44). IL-23 may facilitate the expansion of certain T cell subsets, instrumental in promoting CLL clonal expansion. The absence of this T cell support in NSG mice exposed to a neutralizing anti-IL-23 antibody would provide an explanation for the efficiency of the treatment in eradicating the engrafted leukemic clone. This hypothesis seems to be preferable to that of a direct cytotoxicity of $\alpha \mathrm{IL}-23 \mathrm{p} 19 \mathrm{mAb}$ on CLL cells growing in NSG mice.

Together, the above observations indicate that the activation of the IL-23R complex/IL-23 loop depends on a number of variables including CLL cell contact with CD40L-expressing cells, JAK/STAT pathway activation, and $\mathrm{T}$ cell composition. Moreover, these factors 
A

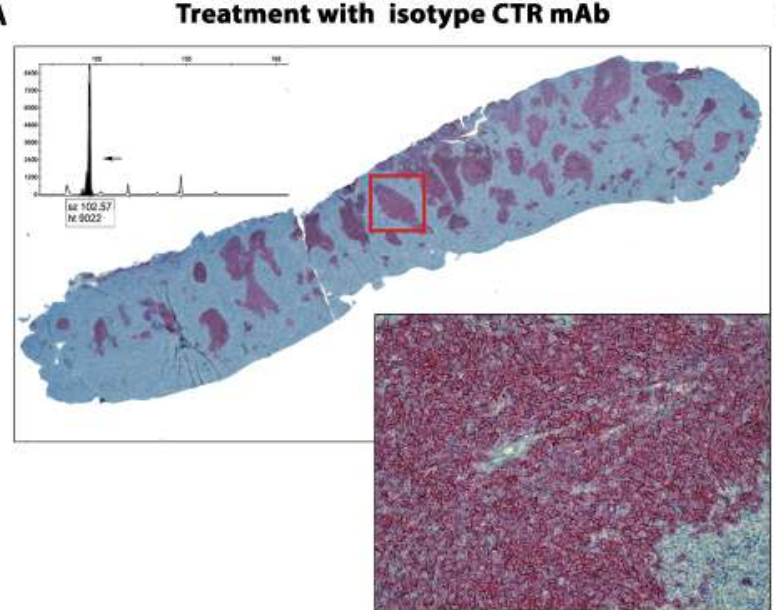

C

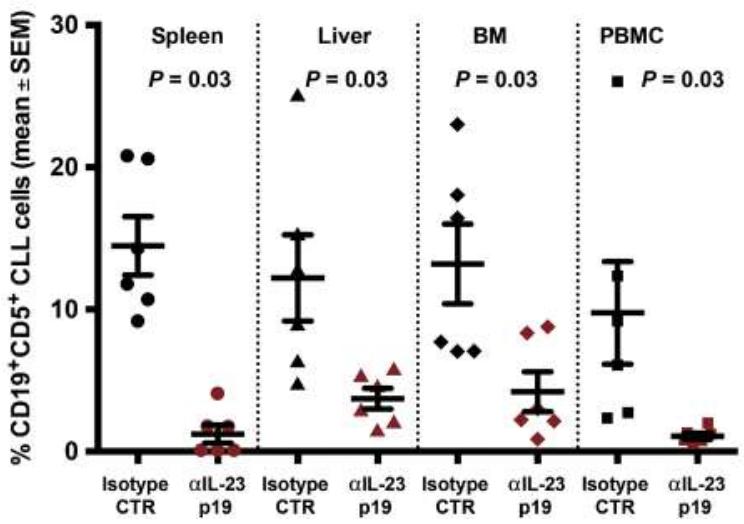

require particular trafficking conditions in peripheral lymphoid tissues, to efficiently exert their function, as documented by the heterogeneity of neoplastic cell distribution in the LNs and the relationship of these cells with different microenvironmental cell components. Given these considerations, it is not surprising to find different degrees of CLL activation among cell clones from different patients or to observe differences in the plasma levels of IL-23 as reported in another study (45). Unfortunately, such determination could not be performed in the present cohort because of the lack of sera availability. Reevaluation of IL-23 mRNA levels in the circulating CLL cells from the patient cohort of this study, obtained from a previous gene expression profile investigation (28), revealed no correlation between the mRNA levels and the classification of a case as IL- $23^{\text {high }}$ or IL- $23^{\text {low }}$, or the presence of unfavorable prognostic markers, possibly reiterating the concepts that the events occurring in peripheral lymphoid organs are the most relevant in determining the activation of the IL-23R complex/IL-23 loop, the levels of plasma IL-23, and perhaps the patient's clinical course.

Inconsistent with the present observations are studies in different lymphoproliferative disorders that have reported either an inhibitory effect of IL-23 on the growth of the neoplastic cells (DLBCL, FL, and ALL) or no effect (myeloma) (23-26). The reasons for these discrepancies are presently obscure. Tentatively, one could speculate that cells from different neoplasms could respond differently to IL-23 exposure, owing to differences in activation status in vivo.

The in vivo xenograft experiments demonstrated the effective dependence of IL-23R complex regulation by the tissue microenviron-
B

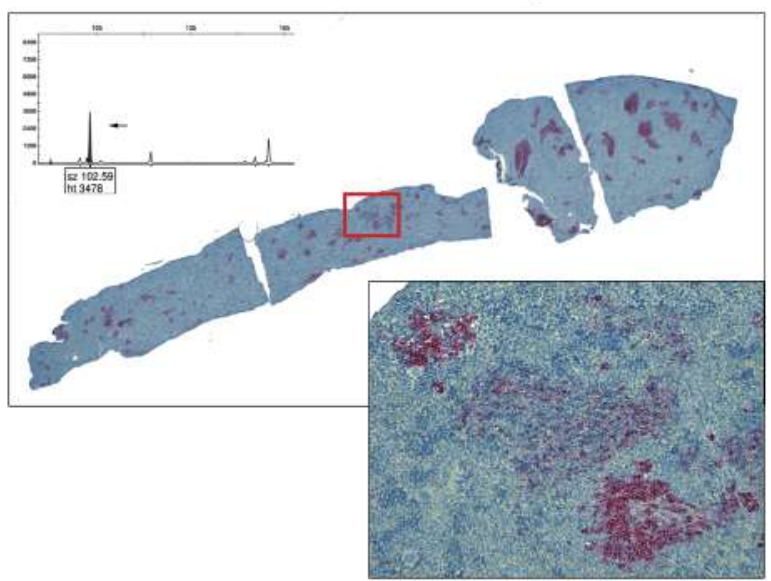

Fig. 8. $\alpha$ IL-23p19 induces regression of the leukemic clone for a prolonged period. Mice were injected with $100 \times 10^{6} \mathrm{CLL}$ cells per mouse (CLL GE2-RL201). After 2 weeks, blood samples were evaluated for the presence of circulating leukemic cells before treatment with four doses of $\alpha$ IL-23p 19 or isotype CTR mAb every 2 days. Three weeks after the last $m A b$ dose, mice were sacrificed, and the spleen, liver, BM, and peripheral blood were analyzed by $\mathrm{IHC}$ and flow cytometry. (A and B) Lowmagnification image of longitudinal sections of paraffin-embedded mouse spleen stained with $\alpha \mathrm{CD} 20-\mathrm{Ab}$. The insets show infiltrating foci observed at higher magnification $(\times 200)$. Black peaks indicated by the arrows in the graph insets show the presence of $B$ cell receptor gene rearrangement of the leukemic clone as assessed by fragment length analysis. Microphotographs are representative of analyses on at least 10 microscopic fields performed on each mouse spleen tissue sample. (C) Spleen, liver, BM, and peripheral blood samples analyzed by flow cytometry for percentage of neoplastic $B$ cells $\left(\mathrm{CD}^{+} \mathrm{CD} 19^{+}\right.$cells). The mean and SEM of 12 mice injected with CLL cells from two different cases (SD36 and GE2-RL201) are shown (Wilcoxon test).

ment. Notably, we did not find any differences in CLL cell engraftment in NSG mice of clones classified as either IL- $23^{\text {high }}$ or IL- $23^{\text {low }}$. This observation may have two non-mutually exclusive explanations: (i) that engraftment was greatly facilitated not only by the presence of the patient $\mathrm{T}$ cells but also by their preactivation step with $\mathrm{CD} 3 / \mathrm{CD} 28$ beads and IL-2 to which all CLL PBMC suspensions are routinely subjected before inoculation in our laboratory, or (ii) that the murine environment represented a suitable milieu for the full activation of the IL-23R complex/IL-23 loop. The present experiments demonstrated the efficacy of a mAb-based interference of the IL-23R/IL-23 axis in CLL disease control and eradication. The use of an $\alpha \mathrm{IL}-23 \mathrm{p} 19$ antibody, currently adopted in the clinical setting for the treatment of autoimmune diseases (46), represents a strong prospect for the translation of the results from our in vivo animal studies, although they were limited to a single model dependent on immunodeficient mice. This study indicates that the JAK/STAT pathway may represent an additional suitable therapeutic target for CLL, as in diseases characterized by IL-23-driven lymphocyte proliferation. Thus, an antiIL-23 mAb and JAK/STAT inhibitor alone or in combination may represent a future tool for the treatment of a disease that, so far, appears to be incurable $(47,48)$.

\section{MATERIALS AND METHODS Study design}

The aim of this work was to determine the role of the IL-23R/IL-23 autocrine loop in CLL clonal survival/expansion and to ascertain 
whether this loop is drug-targetable. This study was generated by the observation that cells from CLL clones can express different levels of IL-23R and that CLL cases classified as IL-23R ${ }^{\text {high }}$ have a shorter TTFT than cases classified as IL-23 ${ }^{\text {low }}$. Therefore, IL-23R could conceivably be part of a series of events leading to clonal expansion. To investigate this hypothesis, we first studied whether a fully functional IL-23R complex could be induced on CLL by a number of stimuli. CLL cells from both IL-23 $3^{\text {high }}$ and IL-2 $3^{\text {low }}$ patient groups expressed IL-23R complex and began to secrete IL-23 when activated in vitro by contact with CD40L-expressing cells. This activation process was accompanied by increased cell viability, by decreased spontaneous apoptosis, and by cell proliferation. To investigate whether this CD40Lmediated activation process also occurred in vivo, we first observed LN from CLL patients by IHC and found that IL-23R complex-expressing and IL-23-secreting CLL cells were located primarily at sites enriched of CD40L ${ }^{+}$cells. To further investigate the potential role of an IL-23R complex/IL-23 autocrine/paracrine loop, we inoculated the CLL cells into NSG mice together with activated autologous T cells. Groups of these mice were treated with a neutralizing $\alpha$ IL-23p19 mAb, whereas control mice received an irrelevant mAb. $\alpha$ IL-23p19 mAb-treated mice displayed a substantial inhibition of CLL cell growth compared to control mice. In situ studies showing IL-23 production as well as IL-23R complex expression particularly at the site of CLL cell growth expansion confirmed this notion.

Data are presented as mean \pm SEM or mean $\pm S D$, which were calculated invariably from $n$ (the number of patients or animals, biological replicates). Primary data are reported in table S5.

\section{Statistical analysis}

The statistical software package SPSS for Windows, v.13.0, 2004 (SPSS UK), was used for all analyses. For categorical variables, statistical comparisons were performed using two-way tables for Fisher's exact test and multiway tables for Pearson's chi-square test. Statistical comparisons between related samples were carried out by Wilcoxon or Mann-Whitney $U$ tests.

The best cutoff point for IL-23R expression able to discriminate cases that progressed from those that did not progress was sought by constructing ROCs. TTFT analyses were performed using the Kaplan-Meier method. Statistical significance of associations between individual variables and survival was calculated using the log-rank test. The prognostic impact for the outcome variable was investigated by univariate and multiple Cox regression analysis. Data are expressed as $\mathrm{HR}$ and $95 \% \mathrm{CI}$. To assess the internal validity of univariate and multivariate Cox regression models, we performed a bootstrap resampling technique of 1000 samples (49). $P<0.05$ was considered significant for all statistical calculations. Values are given as mean \pm SEM or mean \pm SD.

\section{SUPPLEMENTARY MATERIALS}

www.sciencetranslationalmedicine.org/cgi/content/full/10/428/eaal1571/DC1 Materials and Methods

Fig. S1. Gating strategy to analyze IL-23R complex induction after activation by CD40Lexpressing fibroblasts.

Fig. S2. IL-12R 11 mRNA production after CLL cell activation by CD40L-expressing fibroblasts. Fig. S3. Expression of a complete IL-23R by CLL cells after depletion of IL-23R-positive cells and coculture with autologous activated T cells.

Fig. S4. Demonstration of intracytoplasmic IL-23 chains in CLL cells.

Fig. S5. HS5 stromal cells do not express CD40L.

Fig. S6. Enhanced IL-23R complex expression by coculture of PBMC with NLC.

Fig. S7. IL-23R complex expression by CLL cells cocultured with stromal cells or NLCs.
Fig. S8. Relationship between the BCR signaling pathway and IL-23R complex expression in CLL cells.

Fig. S9. Silencing of IL-23A or IL-23R genes by siRNA.

Fig. S10. STAT3 phosphorylation induced by CLL cell exposure to IL-23.

Fig. S11. NSG mice engrafted with CLL cells.

Fig. S12. Minimal residual disease detection in mice tissues after treatment with $\alpha$ IL-23p19. Fig. S13. Anti-IL-23p19 mAb does not induce antibody-dependent cytotoxicity.

Fig. S14. Schematic representation of the IL-23R complex/IL-23 axis in CLL.

Table S1. Relationship between IL-23R chain expression and prognostic parameters.

Table S2. Univariate and multivariate bootstrapping validated Cox regression analysis of TTFT.

Table S3. Features of the CLL cases used in coculture experiments with CD40L-expressing fibroblasts (CD40L-TC).

Table S4. Summary of the features of all CLL cases whose cells were used for xenograft tests. Table S5. Primary data.

References (50-53)

\section{REFERENCES AND NOTES}

1. N. Chiorazzi, K. R. Rai, M. Ferrarini, Chronic lymphocytic leukemia. N. Engl. J. Med. 352, 804-815 (2005).

2. D. F. Quail, J. A. Joyce, Microenvironmental regulation of tumor progression and metastasis. Nat. Med. 19, 1423-1437 (2013).

3. C. Tripodo, S. Sangaletti, P. P. Piccaluga, S. Prakash, G. Franco, I. Borrello, A. Orazi, M. P. Colombo, S. A. Pileri, The bone marrow stroma in hematological neoplasmsA guilty bystander. Nat. Rev. Clin. Oncol. 8, 456-466 (2011).

4. G. Franco, C. Guarnotta, B. Frossi, P. P. Piccaluga, E. Boveri, A. Gulino, F. Fuligni, A. Rigoni, R. Porcasi, S. Buffa, E. Betto, A. M. Florena, V. Franco, E. Iannitto, L. Arcaini, S. A. Pileri, C. Pucillo, M. P. Colombo, S. Sangaletti, C. Tripodo, Bone marrow stroma CD40 expression correlates with inflammatory mast cell infiltration and disease progression in splenic marginal zone lymphoma. Blood 123, 1836-1849 (2014).

5. J. A. Burger, J. G. Gribben, The microenvironment in chronic lymphocytic leukemia (CLL) and other B cell malignancies: Insight into disease biology and new targeted therapies. Semin. Cancer Biol. 24, 71-81 (2014).

6. B. T. Messmer, D. Messmer, S. L. Allen, J. E. Kolitz, P. Kudalkar, D. Cesar, E. J. Murphy, P. Koduru, M. Ferrarini, S. Zupo, G. Cutrona, R. N. Damle, T. Wasil, K. R. Rai, M. K. Hellerstein, N. Chiorazzi, In vivo measurements document the dynamic cellular kinetics of chronic lymphocytic leukemia B cells. J. Clin. Invest. 115, 755-764 (2005).

7. C. Calissano, R. N. Damle, G. Hayes, E. J. Murphy, M. K. Hellerstein, C. Moreno, C. Sison, M. S. Kaufman, J. E. Kolitz, S. L. Allen, K. R. Rai, N. Chiorazzi, In vivo intraclonal and interclonal kinetic heterogeneity in B-cell chronic lymphocytic leukemia. Blood 114, 4832-4842 (2009).

8. E. ten Hacken, J. A. Burger, Molecular pathways: Targeting the microenvironment in chronic lymphocytic leukemia-Focus on the B-cell receptor. Clin. Cancer Res. 20, 548-556 (2014).

9. R. Rosenquist, F. Davi, P. Ghia, The microenvironment in lymphomas-Dissecting the complex crosstalk between tumor cells and 'by-stander' cells. Semin. Cancer Biol. 24, 1-2 (2014).

10. P. Ghia, N. Chiorazzi, K. Stamatopoulos, Microenvironmental influences in chronic lymphocytic leukaemia: The role of antigen stimulation. J. Intern. Med. 264, 549-562 (2008).

11. X.-J. Yan, I. Dozmorov, W. Li, S. Yancopoulos, C. Sison, M. Centola, P. Jain, S. L. Allen, J. E. Kolitz, K. R. Rai, N. Chiorazzi, B. Sherry, Identification of outcome-correlated cytokine clusters in chronic lymphocytic leukemia. Blood 118, 5201-5210 (2011).

12. U. Rozovski, M. J. Keating, Z. Estrov, Targeting inflammatory pathways in chronic lymphocytic leukemia. Crit. Rev. Oncol. Hematol. 88, 655-666 (2013).

13. L. Borche, A. Lim, J. L. Binet, G. Dighiero, Evidence that chronic lymphocytic leukemia B lymphocytes are frequently committed to production of natural autoantibodies. Blood 76, 562-569 (1990).

14. Z. M. Sthoeger, M. Wakai, D. B. Tse, V. P. Vinciguerra, S. L. Allen, D. R. Budman, S. M. Lichtman, P. Schulman, L. R. Weiselberg, N. Chiorazzi, Production of autoantibodies by $C D 5$-expressing $B$ lymphocytes from patients with chronic lymphocytic leukemia. J. Exp. Med. 169, 255-268 (1989).

15. M. Dühren-von Minden, R. Übelhart, D. Schneider, T. Wossning, M. P. Bach, M. Buchner, D. Hofmann, E. Surova, M. Follo, F. Köhler, H. Wardemann, K. Zirlik, H. Veelken, H. Jumaa, Chronic lymphocytic leukaemia is driven by antigen-independent cell-autonomous signalling. Nature 489, 309-312 (2012).

16. A. Lanemo Myhrinder, E. Hellqvist, E. Sidorova, A. Söderberg, H. Baxendale, C. Dahle, K. Willander, G. Tobin, E. Bäckman, O. Söderberg, R. Rosenquist, S. Hörkkö, A. Rosén, A new perspective: Molecular motifs on oxidized LDL, apoptotic cells, and bacteria are targets for chronic lymphocytic leukemia antibodies. Blood 111, 3838-3848 (2008).

17. R. Catera, G. J. Silverman, K. Hatzi, T. Seiler, S. Didier, L. Zhang, M. Hervé, E. Meffre, D. G. Oscier, H. Vlassara, R. H. Scofield, Y. Chen, S. L. Allen, J. Kolitz, K. R. Rai, C. C. Chu, 
N. Chiorazzi, Chronic lymphocytic leukemia cells recognize conserved epitopes associated with apoptosis and oxidation. Mol. Med. 14, 665-674 (2008).

18. C. C. Chu, R. Catera, L. Zhang, S. Didier, B. M. Agagnina, R. N. Damle, M. S. Kaufman, J. E. Kolitz, S. L. Allen, K. R. Rai, N. Chiorazzi, Many chronic lymphocytic leukemia antibodies recognize apoptotic cells with exposed nonmuscle myosin heavy chain IIA: Implications for patient outcome and cell of origin. Blood 115, 3907-3915 (2010).

19. E. Volpe, N. Servant, R. Zollinger, S. I. Bogiatzi, P. Hupé, E. Barillot, V. Soumelis, A critical function for transforming growth factor- $\beta$, interleukin 23 and proinflammatory cytokines in driving and modulating human $\mathrm{T}_{\mathrm{H}}-17$ responses. Nat. Immunol. 9, 650-657 (2008).

20. C. A. Hunter, New IL-12-family members: IL-23 and IL-27, cytokines with divergent functions. Nat. Rev. Immunol. 5, 521-531 (2005).

21. J. L. Langowski, X. Zhang, L. Wu, J. D. Mattson, T. Chen, K. Smith, B. Basham, T. McClanahan, R. A. Kastelein, M. Oft, IL-23 promotes tumour incidence and growth. Nature 442, 461-465 (2006).

22. M. W. L. Teng, E. P. Bowman, J. J. McElwee, M. J. Smyth, J.-L. Casanova, A. M. Cooper, D. J. Cua, IL-12 and IL-23 cytokines: From discovery to targeted therapies for immunemediated inflammatory diseases. Nat. Med. 21, 719-729 (2015).

23. C. Cocco, S. Canale, C. Frasson, E. Di Carlo, E. Ognio, D. Ribatti, I. Prigione, G. Basso, I. Airoldi, Interleukin-23 acts as antitumor agent on childhood B-acute lymphoblastic leukemia cells. Blood 116, 3887-3898 (2010).

24. C. Cocco, F. Morandi, I. Airoldi, Interleukin-27 and interleukin- 23 modulate human plasmacell functions. J. Leukoc. Biol. 89, 729-734 (2011).

25. C. Cocco, E. Di Carlo, S. Zupo, S. Canale, A. Zorzoli, D. Ribatti, F. Morandi, E. Ognio, I. Airoldi, Complementary IL-23 and IL-27 anti-tumor activities cause strong inhibition of human follicular and diffuse large B-cell lymphoma growth in vivo. Leukemia $\mathbf{2 6}$ 1365-1374 (2012).

26. N. Giuliani, I. Airoldi, Novel insights into the role of interleukin-27 and interleukin-23 in human malignant and normal plasma cells. Clin. Cancer Res. 17, 6963-6970 (2011).

27. M. Hallek, B. D. Cheson, D. Catovsky, F. Caligaris-Cappio, G. Dighiero, H. Döhner, P. Hillmen, M. J. Keating, E. Montserrat, K. R. Rai, T. J. Kipps; International Workshop on Chronic Lymphocytic Leukemia, Guidelines for the diagnosis and treatment of chronic lymphocytic leukemia: A report from the International Workshop on Chronic Lymphocytic Leukemia updating the National Cancer Institute-Working Group 1996 guidelines. Blood 111, 5446-5456 (2008).

28. F. Morabito, L. Mosca, G. Cutrona, L. Agnelli, G. Tuana, M. Ferracin, B. Zagatti, M. Lionetti, S. Fabris, F. Maura, S. Matis, M. Gentile, E. Vigna, M. Colombo, C. Massucco, A. G. Recchia, S. Bossio, L. De Stefano, F. Ilariucci, C. Musolino, S. Molica, F. Di Raimondo, A. Cortelezzi, P. Tassone, M. Negrini, S. Monti, D. Rossi, G. Gaidano, M. Ferrarini, A. Neri, Clinical monoclonal B lymphocytosis versus Rai 0 chronic lymphocytic leukemia: A comparison of cellular, cytogenetic, molecular, and clinical features. Clin. Cancer Res. 19, 5890-5900 (2013).

29. S. Bruno, F. Ghiotto, C. Tenca, A. N. Mazzarello, M. Bono, P. Luzzi, S. Casciaro, A. Recchia, A. DeCensi, F. Morabito, F. Fais, $\mathrm{N}$-(4-hydroxyphenyl)retinamide promotes apoptosis of resting and proliferating B-cell chronic lymphocytic leukemia cells and potentiates fludarabine and ABT-737 cytotoxicity. Leukemia 26, 2260-2268 (2012).

30. N. Tsukada, J. A. Burger, N. J. Zvaifler, T. J. Kipps, Distinctive features of "nurselike" cells that differentiate in the context of chronic lymphocytic leukemia. Blood 99, 1030-1037 (2002).

31. I. Gehrke, R. K. Gandhirajan, S. J. Poll-Wolbeck, M. Hallek, K.-A. Kreuzer, Bone marrow stromal cell-derived vascular endothelial growth factor (VEGF) rather than chronic lymphocytic leukemia (CLL) cell-derived VEGF is essential for the apoptotic resistance of cultured CLL cells. Mol. Med. 17, 619-627 (2011).

32. P. Giannoni, G. Pietra, G. Travaini, R. Quarto, G. Shyti, R. Benelli, L. Ottaggio, M. C. Mingari, S. Zupo, G. Cutrona, I. Pierri, E. Balleari, A. Pattarozzi, M. Calvaruso, C. Tripodo, M. Ferrarini, D. de Totero, Chronic lymphocytic leukemia nurse-like cells express hepatocyte growth factor receptor (c-MET) and indoleamine 2,3-dioxygenase and display features of immunosuppressive type 2 skewed macrophages. Haematologica 99, 1078-1087 (2014).

33. A. Petlickovski, L. Laurenti, X. Li, S. Marietti, P. Chiusolo, S. Sica, G. Leone, D. G. Efremov, Sustained signaling through the B-cell receptor induces $\mathrm{Mcl}-1$ and promotes survival of chronic lymphocytic leukemia B cells. Blood 105, 4820-4827 (2005).

34. D. Bagnara, M. S. Kaufman, C. Calissano, S. Marsilio, P. E. M. Patten, R. Simone, P. Chum, X.-J. Yan, S. L. Allen, J. E. Kolitz, S. Baskar, C. Rader, H. Mellstedt, H. Rabbani, A. Lee, P. K. Gregersen, K. R. Rai, N. Chiorazzi, A novel adoptive transfer model of chronic lymphocytic leukemia suggests a key role for T lymphocytes in the disease. Blood 117, 5463-5472 (2011).

35. G. Cutrona, S. Matis, M. Colombo, C. Massucco, G. Baio, F. Valdora, L. Emionite, S. Fabris, A. G. Recchia, M. Gentile, C. E. Neumaier, D. Reverberi, R. Massara, S. Boccardo, L. Basso, S. Salvi, F. Rosa, M. Cilli, S. Zupo, M. Truini, P. Tassone, M. Calabrese, M. Negrini, A. Neri, F. Morabito, F. Fais, M. Ferrarini, Effects of miRNA-15 and miRNA-16 expression replacement in chronic lymphocytic leukemia: Implication for therapy. Leukemia 31, 1894-1904 (2017).
36. V. C. Kyttaris, O. Kampagianni, G. C. Tsokos, Treatment with anti-interleukin 23 antibody ameliorates disease in lupus-prone mice. Biomed. Res. Int. 2013, 861028 (2013).

37. N. M. Moutsopoulos, C. S. Zerbe, T. Wild, N. Dutzan, L. Brenchley, G. DiPasquale, G. Uzel, K. C. Axelrod, A. Lisco, L. D. Notarangelo, G. Hajishengallis, L. D. Notarangelo, S. M. Holland, Interleukin-12 and interleukin-23 blockade in leukocyte adhesion deficiency type 1. N. Engl. J. Med. 376, 1141-1146 (2017).

38. S. Zupo, L. Isnardi, M. Megna, R. Massara, F. Malavasi, M. Dono, E. Cosulich, M. Ferrarini, CD38 expression distinguishes two groups of B-cell chronic lymphocytic leukemias with different responses to anti-IgM antibodies and propensity to apoptosis. Blood $\mathbf{8 8}$, 1365-1374 (1996).

39. R. M. Young, L. M. Staudt, Targeting pathological B cell receptor signalling in lymphoid malignancies. Nat. Rev. Drug Discov. 12, 229-243 (2013).

40. D. Kitamura, J. Roes, R. Kühn, K. Rajewsky, A B cell-deficient mouse by targeted disruption of the membrane exon of the immunoglobulin $\mu$ chain gene. Nature $350,423-426$ (1991).

41. S. E. M. Herman, X. Sun, E. M. McAuley, M. M. Hsieh, S. Pittaluga, M. Raffeld, D. Liu, K. Keyvanfar, C. M. Chapman, J. Chen, J. J. Buggy, G. Aue, J. F. Tisdale, P. Pérez-Galán, A. Wiestner, Modeling tumor-host interactions of chronic lymphocytic leukemia in xenografted mice to study tumor biology and evaluate targeted therapy. Leukemia 27, 2311-2321 (2013).

42. C. Parham, M. Chirica, J. Timans, E. Vaisberg, M. Travis, J. Cheung, S. Pflanz, R. Zhang, K. P. Singh, F. Vega, W. To, J. Wagner, A.-M. O'Farrell, T. McClanahan, S. Zurawski, C. Hannum, D. Gorman, D. M. Rennick, R. A. Kastelein, R. de Waal Malefyt, K. W. Moore, A receptor for the heterodimeric cytokine IL-23 is composed of IL-12Rß1 and a novel cytokine receptor subunit, IL-23R. J. Immunol. 168, 5699-5708 (2002).

43. D. D. Patel, V. K. Kuchroo, Th17 cell pathway in human immunity: Lessons from genetics and therapeutic interventions. Immunity 43, 1040-1051 (2015).

44. F. McClanahan, J. C. Riches, S. Miller, W. P. Day, E. Kotsiou, D. Neuberg, C. M. Croce, M. Capasso, J. G. Gribben, Mechanisms of PD-L1/PD-1-mediated CD8 T-cell dysfunction in the context of aging-related immune defects in the E $\mu$-TCL1 CLL mouse model. Blood 126, 212-221 (2015).

45. B. Sherry, P. Jain, P. Y. Chiu, L. Leung, S. L. Allen, J. E. Kolitz, K. R. Rai, J. Barrientos, S. Liang, R. Hawtin, N. Chiorazzi, Identification and characterization of distinct IL-17F expression patterns and signaling pathways in chronic lymphocytic leukemia and normal B lymphocytes. Immunol. Res. 63, 216-227 (2015).

46. K. Beroukhim, M. J. Danesh, C. Nguyen, A. Austin, J. Koo, E. Levin, Anti-IL-23 phase II data for psoriasis: A review. J. Drugs Dermatol. 14, 1093-1096 (2015).

47. D. Gladman, W. Rigby, V. F. Azevedo, F. Behrens, R. Blanco, A. Kaszuba, E. Kudlacz, C. Wang, S. Menon, T. Hendrikx, K. S. Kanik, Tofacitinib for psoriatic arthritis in patients with an inadequate response to TNF inhibitors. N. Engl. J. Med. 377, 1525-1536 (2017).

48. P. Mease, S. Hall, O. FitzGerald, D. van der Heijde, J. F. Merola, F. Avila-Zapata, D. Cieślak, D. Graham, C. Wang, S. Menon, T. Hendrikx, K. S. Kanik, Tofacitinib or adalimumab versus placebo for psoriatic arthritis. N. Engl. J. Med. 377, 1537-1550 (2017).

49. E. W. Steyerberg, Clinical Prediction Model: A Practical Approach to Development, Validation and Updating (Springer, 2009).

50. D. de Totero, R. Meazza, M. Capaia, M. Fabbi, B. Azzarone, E. Balleari, M. Gobbi, G. Cutrona, M. Ferrarini, S. Ferrini, The opposite effects of IL-15 and IL-21 on CLL B cells correlate with differential activation of the JAK/STAT and ERK1/2 pathways. Blood 111, 517-524 (2008).

51. C. Tripodo, S. Sangaletti, C. Guarnotta, P. P. Piccaluga, M. Cacciatore, M. Giuliano, G. Franco, C. Chiodoni, M. Sciandra, S. Miotti, G. Calvaruso, A. Carè, A. M. Florena, K. Scotlandi, A. Orazi, S. A. Pileri, M. P. Colombo, Stromal SPARC contributes to the detrimental fibrotic changes associated with myeloproliferation whereas its deficiency favors myeloid cell expansion. Blood 120, 3541-3554 (2012).

52. G. R. Owen, L. Häkkinen, C. Wu, H. Larjava, A reproducible technique for specific labeling of antigens using preformed fluorescent molecular lgG-F(ab')2 complexes from primary antibodies of the same species. Microsc. Res. Tech. 73, 623-630 (2010).

53. M. Colombo, G. Cutrona, D. Reverberi, S. Fabris, A. Neri, M. Fabbi, G. Quintana, G. Quarta, F. Ghiotto, F. Fais, M. Ferrarini, Intraclonal cell expansion and selection driven by B cell receptor in chronic lymphocytic leukemia. Mol. Med. 17, 834-839 (2011).

Acknowledgments: In addition to the listed authors, the following investigators participated in this study as part of the Gruppo Italiano Studio Linfomi: G. Quintana (Divisione di Ematologia, Presidio Ospedaliero "A. Perrino," Brindisi), G. Bertoldero (Dipartimento di Oncologia, Ospedale Civile, Noale, Venezia), P. Di Tonno (Dipartimento di Ematologia, Venere, Bari), R. Foà and F. R. Mauro (Divisione di Ematologia, Università La Sapienza, Roma), N. Di Renzo (Unità di Ematologia, Ospedale Vito Fazzi, Lecce), M. C. Cox [Ematologia, Azienda Ospedaliera (AO) Sant'Andrea, Università La Sapienza, Roma], S. Molica (Dipartimento di Oncologia ed Ematologia, Pugliese-Ciaccio Hospital, Catanzaro), A. Guarini (Unità di Ematologia e Trapianto di Cellule Staminali, Istituto di Oncologia "Giovanni Paolo II," Bari), A. Abbadessa [Unitá operativa complessa (UOC) di Oncoematologia Ospedale 
"S. Anna e S. Sebastiano," Caserta], F. Iuliano (UOC di Oncologia, Ospedale Giannettasio, Rossano Calabro, Cosenza), O. Racchi (Ospedale Villa Scassi Sampierdarena, Genova), M. Spriano (Ematologia, AO San Martino, Genova), F. Ferrara (Divisione di Ematologia, Ospedale Cardarelli, Napoli), M. Crugnola [Ematologia, Centro Trapianti Midollo Osseo (CTMO), Azienda Ospedaliera Universitaria (AOU) di Parma], A. Andriani (Dipartimento di Ematologia, Ospedale Nuovo Regina Margherita, Roma), N. Cascavilla [Unità di Ematologia e Trapianto di Cellule Staminali, Istituto di Ricovero e Cura a Carattere Scientifico (IRCCS) Ospedale Casa Sollievo della Sofferenza, San Giovanni Rotondo], L. Ciuffreda (Unità di Ematologia, Ospedale San Nicola Pellegrino, Trani), G. Pinotti (Unità Operativa Oncologia Medica, Ospedale di Circolo Fondazione Macchi, Varese), A. Pascarella (Unità Operativa di Ematologia, Ospedale dell'Angelo, Venezia-Mestre), M. G. Lipari (Divisione di Ematologia, Ospedale Policlinico, Palermo, Francesco Merli, Unità Operativa di Ematologia, Arcispedale Santa Maria Nuova, Reggio Emilia), L. Baldini (Istituto di Ricovero e Cura a Carattere Scientifico Cà GrandaMaggiore Policlinico, Milano), C. Musolino (Divisione di Ematologia, Università di Messina), A. Cortelezzi (Ematologia and CTMO, Foundation IRCCS Ca' Granda Ospedale Maggiore Policlinico, Milano), F. Angrilli (Dipartimento di Ematologia, Ospedale Santo Spirito, Pescara), U. Consoli (Unità Operativa semplice di Emato-Oncologia, Ospedale Garibaldi-Nesima, Catania), G. Festini (Centro di Riferimento Ematologico-Seconda Medicina, AOU, Ospedali Riuniti, Trieste), G. Longo (Unità di Ematologia, Ospedale San Vincenzo, Taormina), D. Vallisa and A. Arcari (Unità di Ematologia, Dipartimento di Onco-Ematologia, Guglielmo da Saliceto Hospital, Piacenza), F. Di Raimondo and A. Chiarenza (Divisione di Ematologia, Università di Catania Ospedale Ferrarotto, Catania), I. Vincelli (Unità di Ematologia, AO of Reggio Calabria), and D. Mannina (Divisione di Ematologia, Ospedale Papardo, Messina, Italy). Funding: This work was supported by Associazione Italiana Ricerca sul Cancro (AIRC) Grant $5 \times$ mille n.9980 (to M. Ferrarini, F.M., and A.N.) and n.12162 (to C.T.) and by AIRC Investigator Grant (IG) n.14326 (to M. Ferrarini), n.15999 (to C.T.), n.10136 and 16722 (A.N.), n.15426 (to F.F.), n.13518 (to S. Ferrini), and n. 17047 (to I.A.). AIRC and Fondazione Cassa di Risparmio di Calabria e di Lucania (CaRiCal) cofinanced Multi-Unit Regional Grant 2014 n.16695 (to F.M.). This work was also supported by Italian Ministry of Health $5 \times 1000$ funds 2013 (to S. Ferrini, S.Z., A.I., and F.F.) and funds 2014 (to S.Z., A.I., and G. Cutrona) and by the RF-2010-2308270 project (to I.A.). A.G.R. was supported by Associazione Italiana contro le Leucemie-Linfomi e Mieloma Cosenza-Fondazione Amelia Scorza. S.M. C.M., M. Colombo, F.V., L.E., S. Bossio, M.P., A.P., and G.I. were supported by AIRC. We thank F. Ghiotto for helpful support in the graphical elaboration of the IL-23R complex/IL-23 loop. Author contributions: Conception and design: G. Cutrona, C.T., F.F., M. Ferrarini, and F.M. Development of methodology: G. Cutrona, S.M., C.M., M. Fabbi, M. Colombo, D.R., R.M., S. Salvi, S. Bossio, M.P., S. Boccardo, L.D.S., A.P., G.I, S.F., D.d.T., and M. Cilli. Acquisition of data: G. Cutrona, S.M., L.E., M. Colombo, S. Sangaletti, A.G., M.M., S. Fabris, S. Salvi, G. Cerruti, F.V., S.Z., M.G., E.V., A.I., F.M., D.d.T., and M. Cardillo. Analysis and interpretation of data: D.d.T., G. Cutrona, A.G.R., S.M., A.N., C.T., S. Sangaletti, A.G., M. Colombo, I.A., S. Ferrini, M. Fabbi, F.F., S.Z., M.G., A.N., M. Ferrarini, and F.M. Writing, review, and/or revision of the manuscript: G. Cutrona, C.T., A.G.R., F.F., M. Ferrarini, and F.M. Study supervision: G. Cutrona and F.M. Competing interests: The authors declare that they have no competing interests. Data and materials availability: NSG mice are available from the Jackson Laboratory under a material transfer agreement with the IRCCS AOU San Martino-Istituto Nazionale per la Ricerca sul Cancro (IST) Genoa.

Submitted 6 October 2016

Resubmitted 28 June 2017

Accepted 15 November 2017

Published 14 February 2018

10.1126/scitransImed.aal1571

Citation: G. Cutrona, C. Tripodo, S. Matis, A. G. Recchia, C. Massucco, M. Fabbi, M. Colombo, L. Emionite, S. Sangaletti, A. Gulino, D. Reverberi, R. Massara, S. Boccardo, D. de Totero, S. Salvi, M. Cilli, M. Pellicanò, M. Manzoni, S. Fabris, I. Airoldi, F. Valdora, S. Ferrini, M. Gentile, E. Vigna, S. Bossio, L. De Stefano, A. Palummo, G. Iaquinta, M. Cardillo, S. Zupo, G. Cerruti, A. Ibatici, A. Neri, F. Fais, M. Ferrarini, F. Morabito, Microenvironmental regulation of the IL-23R/IL-23 axis overrides chronic lymphocytic leukemia indolence. Sci. Transl. Med. 10, eaal1571 (2018). 


\section{Science Translational Medicine}

\section{Microenvironmental regulation of the IL-23R/IL-23 axis overrides chronic lymphocytic leukemia indolence}

Giovanna Cutrona, Claudio Tripodo, Serena Matis, Anna Grazia Recchia, Carlotta Massucco, Marina Fabbi, Monica Colombo, Laura Emionite, Sabina Sangaletti, Alessandro Gulino, Daniele Reverberi, Rosanna Massara, Simona Boccardo, Daniela de Totero, Sandra Salvi, Michele Cilli, Mariavaleria Pellicanò, Martina Manzoni, Sonia Fabris, Irma Airoldi, Francesca Valdora, Silvano Ferrini, Massimo Gentile, Ernesto Vigna, Sabrina Bossio, Laura De Stefano, Angela Palummo, Giovanni laquinta, Martina Cardillo, Simonetta Zupo, Giannamaria Cerruti, Adalberto Ibatici, Antonino Neri, Franco Fais, Manlio Ferrarini and Fortunato Morabito

Sci Transl Med 10, eaal1571.

DOI: 10.1126/scitranslmed.aal1571

Interrupting IL-23 signaling could curb CLL

Chronic lymphocytic leukemia (CLL) cells are derived from B cells, but the exact signals that drive their expansion and survival are not completely understood. Cutrona et al. observed differential expression of the IL-23 receptor on biopsies from early-stage CLL patients, and higher expression was associated with poor prognosis. C LL cells could also produce IL-23 in vitro. The authors reasoned that the cells could produce and respond to this cytokine in a survival feedback loop and demonstrated that an anti-IL-23 antibody could slow tumor growth in a xenograft mouse model. These promising results could open up new avenues of treatment for CLL.

ARTICLE TOOLS

SUPPLEMENTARY MATERIALS

RELATED

REFERENCES

PERMISSIONS http://stm.sciencemag.org/content/10/428/eaal1571

http://stm.sciencemag.org/content/suppl/2018/02/12/10.428.eaal1571.DC1

http://stm.sciencemag.org/content/scitransmed/9/374/eaaj2013.full http://stm.sciencemag.org/content/scitransmed/9/417/eaag1209.full $\mathrm{http}: / / \mathrm{stm}$.sciencemag.org/content/scitransmed/9/413/eaao1214.full

This article cites 52 articles, 22 of which you can access for free http://stm.sciencemag.org/content/10/428/eaal1571\#BIBL

http://www.sciencemag.org/help/reprints-and-permissions

Use of this article is subject to the Terms of Service

Science Translational Medicine (ISSN 1946-6242) is published by the American Association for the Advancement of Science, 1200 New York Avenue NW, Washington, DC 20005. 2017 (C) The Authors, some rights reserved; exclusive licensee American Association for the Advancement of Science. No claim to original U.S. Government Works. The title Science Translational Medicine is a registered trademark of AAAS. 